\title{
Label-free quantitative identification of abnormally ubiquitinated proteins as useful biomarkers for human lung squamous cell carcinomas
}

\author{
Miaolong $\mathrm{Lu}^{1,2,3} \cdot$ Wei Chen ${ }^{4} \cdot$ Wei Zhuang $^{5} \cdot$ Xianquan Zhan $^{1,2,3,6,7}$ (D) \\ Received: 6 October 2019 / Accepted: 12 December 2019 / Published online: 4 January 2020 \\ (C) The Author(s) 2020
}

\begin{abstract}
Background Ubiquitination is an important molecular event in lung squamous cell carcinoma (LSCC), which currently is mainly studied in nonsmall cell lung carcinoma cell models but lacking of ubiquitination studies on LSCC tissues. Here, we presented the ubiquitinated protein profiles of LSCC tissues to explore ubiquitination-involved molecular network alterations and identify abnormally ubiquitinated proteins as useful biomarkers for predictive, preventive, and personalized medicine (PPPM) in LSCC. Methods Anti-ubiquitin antibody-based enrichment coupled with LC-MS/MS was used to identify differentially ubiquitinated proteins (DUPs) between LSCC and control tissues, followed by integrative omics analyses to identify abnormally ubiquitinated protein biomarkers for LSCC.

Results Totally, 400 DUPs with 654 ubiquitination sites were identified,, and motifs A-X (1/2/3)-K* were prone to be ubiquitinated in LSCC tissues. Those DUPs were involved in multiple molecular network systems, including the ubiquitinproteasome system (UPS), cell metabolism, cell adhesion, and signal transduction. Totally, 44 hub molecules were revealed by protein-protein interaction network analysis, followed by survival analysis in TCGA database (494 LSCC patients and 20,530 genes) to obtain 18 prognosis-related mRNAs, of which the highly expressed mRNAs VIM and IGF1R were correlated with poorer prognosis, while the highly expressed mRNA ABCC1 was correlated with better prognosis. VIM-encoded protein vimentin and ABCC1-encoded protein MRP1 were increased in LSCC, which were all associated with poor prognosis. Proteasome-inhibited experiments demonstrated that vimentin and MRP1 were degraded through UPS. Quantitative ubiquitinomics found ubiquitination level was decreased in vimentin and increased in MRP1 in LSCC. These findings showed that the increased vimentin in LSCC might be derived from its decreased ubiquitination level and that the increased MRP1 in LSCC might be derived from its protein synthesis > degradation. GSEA and co-expression gene analyses revealed that VIM and
\end{abstract}

Electronic supplementary material The online version of this article (https://doi.org/10.1007/s13167-019-00197-8) contains supplementary material, which is available to authorized users.

Xianquan Zhan

yjzhan2011@gmail.com

1 Key Laboratory of Cancer Proteomics of Chinese Ministry of Health, Xiangya Hospital, Central South University, 87 Xiangya Road, Changsha 410008, Hunan, People's Republic of China

2 Hunan Engineering Laboratory for Structural Biology and Drug Design, Xiangya Hospital, Central South University, 87 Xiangya Road, Changsha 410008, Hunan, People's Republic of China

3 State Local Joint Engineering Laboratory for Anticancer Drugs, Xiangya Hospital, Central South University, 87 Xiangya Road, Changsha 410008, Hunan, People's Republic of China
4 Shanghai Applied Protein Technology, Shanghai 200233, People's Republic of China

5 Department of Thoracic Surgery, Xiangya Hospital, Central South University, 87 Xiangya Road, Changsha 410008, Hunan, People's Republic of China

6 Department of Oncology, Xiangya Hospital, Central South University, 88 Xiangya Road, Changsha 410008, Hunan, People's Republic of China

7 National Clinical Research Center for Geriatric Disorders, Xiangya Hospital, Central South University, 88 Xiangya Road, Changsha 410008, Hunan, People's Republic of China 
MRP1 were involved in multiple crucial biological processes and pathways. Further, TRIM2 and NEDD4L were predicted as E3 ligases to regulate ubiquitination of vimentin and MRP1, respectively.

Conclusion These findings revealed ubiquitinomic variations and molecular network alterations in LSCC, which is in combination with multiomics analysis to identify ubiquitination-related biomarkers for in-depth insight into the molecular mechanism and therapeutic targets and for prediction, diagnosis, and prognostic assessment of LSCC.

Keywords Lung squamous cell carcinoma - Quantitative ubiquitinomics · Multiomics · Ubiquitin-proteasome system (UPS) · Tumor inflammation · Cell adhesion · Metabolic reprogramming - Signal transduction · Ubiqitination-related biomarker . Predictive preventive personalized medicine (PPPM)

\section{Introduction}

Lung squamous cell carcinoma (LSCC) accounts for approximately $25-30 \%$ of all cases of nonsmall cell lung cancer (NSCLC) with more than $70 \%$ patients diagnosed in advanced stage [1,2] and causes approximately 400,000 deaths per year worldwide [3]. Currently, surgery, radiation, and chemotherapy are still its main treatment. Early diagnosis and targeted drug therapy for LSCC remains a huge clinical challenge in LSCC [3]. The reason is that currently FDA-approved targeted drug therapies, such as epidermal growth factor receptor (EGFR) mutation or EML4-ALK fusion-based targeted therapies, are mainly suitable for lung adenocarcinoma (LUAD) but not for LSCC patients. Although FGFR1 amplification and DDR2 mutation are nominated as "druggable" targets for LSCC patients, their clinical efficacy are still under clinical trials [4, 5]. Early diagnosis and early therapy are an effective approach to improve the survival status of LSCC patients. However, currently, there is a lack of universally accepted biomarkers for early diagnosis and therapeutic targets for LSCC.

It is well-known that LSCC is a complex chronic disease with a series of molecular alterations at the levels of genome, transcriptome, and proteome, and is involved in extensive chronic inflammation in its pathogenesis [6-8]. Predictive, preventive, and personalized medicine (PPPM) is an effective strategy to treat LSCC patients [6-9]. Integrative omics-based biomarkers have important scientific merits for insights into the molecular mechanism, discovery of therapeutic targets, and service for early diagnosis and prognostic assessment of LSCC patients to reduce the mortality and improve patient prognosis $[10,11]$.

Proteome is the final performer of genome and transcriptome and stays in a dynamic balance between protein synthesis and degradation, which was mainly regulated by ubiquitination. Ubiquitination is a common post-translational modification (PTM) [12, 13]. Ubiquitination is involved in multistep reactions catalyzed by a series of enzymes, including ubiquitin-activating enzyme (E1), ubiquitin-conjugating enzyme (E2), and ubiquitin ligase (E3) [14]. Ubiquitin is a 76-amino-acid protein $(8.5 \mathrm{kDa})$, whose carboxyl (C) terminus can be covalently bond to $\varepsilon$-amino group at protein lysine residue [15]. The ubiquitinated proteins are commonly degraded through the ubiquitin-proteasome system (UPS), which mainly degrades short half-life regulatory proteins and structural abnormal, misconstructed, or damaged proteins [16]. Besides protein-degradation functions, ubiquitination also participates in many nonprotein-degrading functions, including internalization and downregulation of receptors, DNA repair, inflammatory signaling, intracellular trafficking, autophagy, enzymatic activity regulation, and assembly of multiprotein complexes [17]. Thus, abnormal ubiquitination is associated with many diseases, including tumor, neurodegenerative disease, and inflammation [18]. For example, a study demonstrated that linear ubiquitination prevented inflammation and regulated immune signaling [19]. Inflammation and ubiquitination all participated in the progress of Alzheimer's disease [20, 21]. As for tumors, UPS dysfunction could either enhance the effect of oncoproteins or reduce the amount of suppressor proteins. Deregulation of E3 ligases contributes to cancer development, and overexpression of E3 ligases is often associated with poor prognosis [22]. Also, E3 ligases can determine the specificity of protein substrates and are themselves "druggable" enzymes, which can serve as potential cancer targets as well as cancer biomarkers. Until now, many tumor therapeutic drugs have been developing based on UPS, such as bortezomib (FDA approved for multiple myeloma and mantle cell lymphoma) [23] and carfilzomib (FDA approved for relapsed and refractory multiple myeloma) [24]. It clearly demonstrates the scientific importance of protein ubiquitination in carcinogenesis and tumor-targeted therapy. Ubiquitinomics study may provide novel insights into the molecular mechanisms and discovery of effective biomarkers for early diagnosis and targeted drug therapy for PPPM in LSCC.

Liquid chromatography-tandem mass spectrometry (LCMS/MS) is a key technique to characterize and quantify ubiquitinated proteins and ubiquitination sites. Although ubiquitination is a low abundance event in the human body, commercially specific anti-K- - -GG antibodies enable to preferentially enrich tryptic ubiquitinated peptides before MS/MS analysis. Anti-ubiquitin antibody (specific anti-K- $\varepsilon-G G$ 
group)-based label-free coupled with LC-MS/MS is an effective method to detect, identify, and quantify ubiquitinated proteins and ubiquitination sites, and more than 10,000 ubiquitination sites have been identified and quantified [25]. Currently, ubiquitinomes of lung cancer cells have been studied $[26,27]$. However, tissue ubiquitinomics has not been reported in LSCC.

Moreover, lung cancer transcriptomics data based on RNA-seq and clinical information can be easily obtained from the public TCGA database, which contains several hundred lung cancer patients $[3,28]$. There have been a large number of studies based on TCGA transcriptomics data and clinical information, which have contributed to PPPM in LSCC, and these works have been systematically reviewed [29]. Integration of ubiquitinomics data and large-scale transcriptomics data with useful clinical information will offer more valuable biomarkers for PPPM in LSCC.

This study used anti-K- $\varepsilon$-GG antibodies-based enrichment in combination with LC-MS/MS to identify differentially ubiquitinated proteins (DUPs) in human LSCC tissues compared to tumor-adjacent control tissues, followed by bioinformatics analysis to reveal functional characteristics of DUPs and ubiquitination-related molecular network alterations. Further, multiomics that integrated DUPs and transcriptomics data were used to investigate in-depth the clinical values of ubiquitination in LSCC for an in-depth understanding of molecular mechanisms, discovery of therapeutic targets, and identification of effective ubiquitination-related biomarkers for PPPM in LSCC.

\section{Materials and methods}

\section{Tissue specimen}

Human LSCC and tumor-adjacent control lung tissues from each lung cancer patient were obtained from the Department of Thoracic surgery, Xiangya Hospital, Central South University. This study was reviewed and approved by the Xiangya Hospital Medical Ethics Committee of Central South University, China. Once the tumor tissue was surgically removed, it was immediately stored in liquid nitrogen. A portion of each tissue sample was removed for pathological diagnosis, and the remainder was stored in an ultra-low temperature freezer $\left(-80^{\circ} \mathrm{C}\right)$ for this study. Clinical characteristics of each sample was collected (Table 1).

\section{Protein extraction}

Five LSCC tissue samples ( $n=5 ; 150 \mathrm{mg}$ per patient) were mixed as LSCC tissue sample $(750 \mathrm{mg}$ ), and five corresponding tumor-adjacent control lung tissues $(n=5 ; 150 \mathrm{mg}$ per patient) were mixed as lung control tissue sample $(750 \mathrm{mg})$.
The mixed LSCC tissues or control tissues were washed in $0.9 \% \mathrm{NaCl}$ solution $(3 \mathrm{~mL}, 5 \times)$ to remove blood contamination, and homogenized in urea lysis buffer including $7 \mathrm{M}$ urea, $2 \mathrm{M}$ thiourea, $100 \mathrm{mM}$ dithiothreitol (DTT), and $1 \mathrm{mM}$ phenylmethyl-sulfonyl fluoride (PMSF). Lysates were sonicated $(80 \mathrm{~W}, 10 \mathrm{~s}$, interval $15 \mathrm{~s} ; 10 \times)$ and centrifuged $\left(15,000 \times g, 20 \mathrm{~min}, 4{ }^{\circ} \mathrm{C}\right)$. The supernatant was collected as protein sample. Protein concentration was measured by the Bradford method.

\section{Trypsin digestion of proteins}

Each sample was treated $\left(600 \mathrm{rpm}, 37^{\circ} \mathrm{C}\right.$, and $\left.1.5 \mathrm{~h}\right)$ with DTT (the final concentration of DTT was $10 \mathrm{mM}$ ) and was kept at room temperature. The DTT-treated sample was treated (dark, $30 \mathrm{~min}$ ) with iodoacetamide (the final concentration of iodoacetamide was $50 \mathrm{mM}$ ). Then, uranyl acetate (UA) was added with an UA final concentration $2 \mathrm{M}$ that was made from UA dilution by $50 \mathrm{mM}$ Tris-HCl buffer ( $\mathrm{pH} 8.0$ ). Each protein sample was digested $\left(37^{\circ} \mathrm{C}, 15-18 \mathrm{~h}\right)$ with trypsin (trypsin:protein = 1:50 at wt:wt). After trypsin digestion, trifluoroacetic acid (TFA) was added (final TFA $=0.1 \%$ ), and $\mathrm{pH}$ was adjusted to $\mathrm{pH} \leq 3$ with $10 \%$ TFA. The tryptic peptides were desalted with $\mathrm{C} 18$ Cartridges (Empore ${ }^{\mathrm{TM}}$ SPE Cartridges C18, bed i.d. $7 \mathrm{~mm}$, volume $3 \mathrm{ml}$, Sigma) and lyophilized.

\section{Enrichment of ubiquitinated peptides}

Each sample was reconstituted with a volume $(1.4 \mathrm{~mL})$ of precooled immunoaffinity purification (IAP) buffer $(50 \mathrm{mM}$ MOPS/ $\mathrm{NaOH} \mathrm{pH} \mathrm{7.2,} 10 \mathrm{mM} \mathrm{Na}_{2} \mathrm{HPO}_{4}$, and $\left.50 \mathrm{mM} \mathrm{NaCl}\right)$.

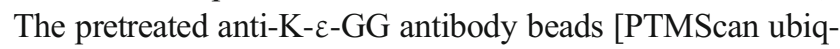

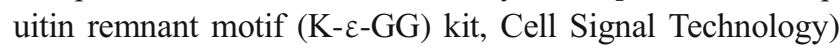
were added to each tryptic peptide sample, incubated $\left(4{ }^{\circ} \mathrm{C}\right.$, $1.5 \mathrm{~h})$, and centrifuged $(2000 \times \mathrm{g}, 30 \mathrm{~s})$. After the supernatant was discarded, the beads with anti-K- $\varepsilon$-GG antibody-binding tryptic peptides were washed with a volume $(1 \mathrm{~mL})$ of precooled IAP buffer $(3 \times)$, and then washed with precooled water $(3 \times)$. A volume $(40 \mu \mathrm{L})$ of $0.15 \%$ TFA was added, followed by incubation (10 $\mathrm{min}$, room temperature) $(2 \times)$ and centrifugation $(2000 \times g, 30 \mathrm{~s})$. The supernatant was the enriched ubiquitinated peptide sample, which was processed to be desalted with C18 STAGE Tips.

\section{LC-MS/MS}

Easy nLC (Proxeon Biosystems, now Thermo Fisher Scientific) coupled with Q Exactive mass spectrometer (Thermo Scientific) was used for LC-MS/MS analysis. The enriched peptides were loaded into a reverse-phase trap column (Thermo Scientific Acclaim PepMap100, $100 \mu \mathrm{m} \times$ 
Table 1 Clinical information of LSCC and control tissue samples

\begin{tabular}{|c|c|c|c|c|c|}
\hline Sample ID & Sex & Age (years) & Smoking status & Pathological diagnosis & Tissues \\
\hline 1 & Female & 49 & 20 years & Right middle and upper LSCC & Cancer; tumor-adjacent normal control tissue \\
\hline 2 & Female & 57 & 40 years & $\begin{array}{l}\text { Right middle and lower high-medium } \\
\text { differentiated LSCC }\end{array}$ & Cancer; tumor-adjacent normal control tissue \\
\hline 3 & Female & 59 & 40 years & Right moderately differentiated LSCC & Cancer; tumor-adjacent normal control tissue \\
\hline 4 & Male & 60 & Nonsmoker & Right moderately differentiated LSCC & Cancer; tumor-adjacent normal control tissue \\
\hline 5 & Female & 46 & 30 years & Right lower high-medium differentiated LSCC & Cancer; tumor-adjacent normal control tissue \\
\hline
\end{tabular}

LSCC = lung squamous cell carcinoma

$2 \mathrm{~cm}$, nanoViper $\mathrm{C} 18$ ) and then online entered into $\mathrm{C} 18$ reversed phase analytical column (Thermo Scientific Easy Column, length $10 \mathrm{~cm}$, i.d. $75 \mu \mathrm{m}$, and $3 \mu \mathrm{m}$ resin) to be separated with buffer A $(0.1 \%$ formic acid) and buffer B ( $84 \%$ acetonitrile and $0.1 \%$ formic acid), in a separation gradient of buffer $\mathrm{B}$ at a flow rate of $300 \mathrm{~nL} / \mathrm{min}$ for $120 \mathrm{~min}$. The mass spectrometer parameters were set as positive-ion mode, selection of a data-dependent top 10 precursor ions for MS/ MS analysis with high-energy collision dissociation (HCD) at $30 \mathrm{eV}$, MS survey scan range $m / z, 300-1800$, automatic gain control (AGC) 3e6, maximum inject time $10 \mathrm{~ms}$, and dynamic exclusion duration $40.0 \mathrm{~s}$. The resolution was 70,000 at $\mathrm{m} / \mathrm{z}$ 200 for MS scan and 17,500 at $\mathrm{m} / \mathrm{z} 200$ for MS/MS scan. The MS/MS raw data for each sample were combined and searched with MaxQuant 1.5.3.17 software to identify and quantify ubiquitinated proteins and ubiquination sites. The main parameters were set as trypsin for enzyme, four missed cleavages, $6 \mathrm{ppm}$ for MS tolerance, $20 \mathrm{ppm}$ for MS/MS tolerance, database uniprot_human_156639_20170105.fasta, carbamidomethyl for fixed modification, oxidation at Met residue, acetylation at protein $\mathrm{N}$-term, and GlyGly at $\mathrm{K}$ residue for variable modification, reverse for decoy database pattern, true for included contaminants, FDR $\leq 0.01$ for peptide, FDR $\leq 0.01$ for ubiquitination site, FDR $\leq 0.01$ for protein, and 2 min for time window (match between runs).

Each ubiquitinated peptide and ubiquitination site was determined with amino acid sequence. The differential ubiquitination level of each ubiquitinated peptide was determined with the ratio (tumor/control) $>2.0$ or $<0.5$, and $p$ value $<0.05$. Proteins containing this type of differentially ubiquitinated peptides were defined as differentially ubiquitinated proteins (DUPs).

\section{Bioinformatics analysis of DUPs in LSCC}

Motif-X (http://motif-x.med.harvard.edu/) was used to predict the ubiquitination motifs with the extracted amino acid sequences that contained the ubiquitination site and seven upstream/downstream amino acid residues from this ubiquitination site (totally 15 amino acid residues) [30, 31].
The Motif-X parameters were set as width 15 , occurrences 20 , background IPI human proteome, and significance threshold 0.0001. For DUPs, the DAVID software (version 6.8, https:// david.ncifcrf.gov/) was used to carry out gene ontology (GO) enrichment analysis, including cellular components (CC), molecular functions (MF), and biological processes (BP), and then those DUPs were clustered into different functional categories [32], with statistical significance $p<0.05$. The statistically significant pathway networks were mined with the Kyoto Encyclopedia of Genes and Genomes (KEGG) pathway analysis. The KEGG online service tool KOBAS (http:// kobas.cbi.pku.cn) was used to annotate the proteins' KEGG database description [33, 34]. The STRING database (https:// string-db.org/) was used to analyze protein-protein interaction (PPI) networks [35]. The STRING results, XGMML format, were imported into Cytoscape (http://www.cytoscape.org/) to visualize the functional networks and calculate the topological properties of the nodes [36].

\section{LSCC transcriptomics data and statistical analysis}

The level 3 gene expression RNA-seq data [20,531 genes; generated from 502 LSCC tissues ( $n=502$ patients) and 51 tumor-adjacent lung control tissues (those 51 lung control tissues belonged to those 502 patients)] and clinical information derived from 494 LSCC patients (those 494 patients had complete prognostic data, and belonged to those 502) in the TCGA database were obtained with UCSC Xena browser (https://xenabrowser.net/) [28]. R package pROC and survival analyses were used to calculate the receiver operating characteristic (ROC) curves for overall survival (OS) and recurrence-free survival (RFS) after initial therapy [37]. The optimal cutoff value for one specific gene was determined based on the Youden index [38]. Log-rank test was performed to assess the difference between the survival curves. The genes co-expressed with VIM and ABCC1 ( $\mid$ Spearman $r \mid \geq 0.5$ ) were examined with cBioPortal for Cancer Genomics (http://www.cbioportal.org/) [39]. Single gene GSEA based on the TCGA database was used to explore the pathway differences between samples with high 
and low expressions of VIM and ABCC1 [40]. The E3substrate interaction network (http://ubibrowser.ncpsb.org/) was used to predict the E3s of VIM and ABCC1 [41].

\section{Cell lines and western blot}

Human LSCC cells H520 were purchased from Central South University (Changsha, China), H226 from the Chinese Academy of Sciences (Shanghai, China), and Calu-1 from the American Type Culture Collection (ATCC) (Manassas, USA). Three cell lines were all cultured in RPMI-1640 medium plus $10 \%$ fetal bovine serum (FBS, Gibco) $\left(5 \% \mathrm{CO}_{2}\right.$ atmosphere, $37^{\circ} \mathrm{C}$ ). For inhibitory analysis of proteasome treated with $10 \mathrm{mM}$ of proteasome inhibitor MG132, each cell line was incubated $(6 \mathrm{~h})$ and then lysed with lysis buffer $[150 \mathrm{mM}$ $\mathrm{NaCl}, 2 \mathrm{mM} \mathrm{NaH}_{2} \mathrm{PO}_{4}, 50 \mathrm{mM}$ Tris- $\mathrm{HCl} \mathrm{pH} 7.5,25 \mathrm{mM} \mathrm{NaF}$, $1 \%$ (v/v) Triton X-100, 2 mM EDTA, 10\% (v/v) glycerol, and protease/phosphatase inhibitor cocktails (Sigma)].

Equal amounts of protein samples were separated with $10 \%$ sodium dodecyl sulfate (SDS)-polyacrylamide gel electrophoresis (PAGE) and transferred onto polyvinylidene difluoride (PVDF) membranes. Proteins on PVDF membrane were incubated $\left(4^{\circ} \mathrm{C}\right.$, overnight) with primary antibodies against VIM-encoded protein vimentin (1:2000; CUSABIO), ABCC1-encoded protein MRP1 (multidrug resistanceassociated protein 1) (1:1000; CUSABIO), IGF1R (1:1000; CUSABIO), and $\beta$-actin $(1: 2000$, Santa Cruz Biotechnology), and then incubated ( $2 \mathrm{~h}$, room temperature) with horseradish peroxidase-conjugated goat anti-rabbit secondary antibody (1:5000; Santa Cruz Biotechnology). ImageJ software (version 1.45s) was used to measure the gray value of the western blot results. The western blot image was digitized to calculate mean $\pm \mathrm{SD}$ with Student's $t$ test $(p<0.05)$.

\section{Results}

\section{DUP profiling in LSCC}

A total of 400 DUPs with 654 ubiquitination sites were identified in LSCC vs. tumor-adjacent control tissues (Supplemental Table 1). A representative MS/MS spectrum of ubiquitinated peptide ${ }^{425}$ ETNLDSLPLVDTHSK $* \mathrm{R}^{440}$ (precursor ion $[\mathrm{M}+2 \mathrm{H}]^{2+} m / z=969.9993$, retention time $\mathrm{RT}=86.77 \mathrm{~min}$, and $\mathrm{K}^{*}=$ ubiquitinated lysine residue) from vimentin (P08670) was shown (Fig. 1a), with high signal to noise $(\mathrm{S} / \mathrm{N})$ ratio and excellent $\mathrm{b}$-ion and $\mathrm{y}$-ion series $\left(\mathrm{b}_{2}, \mathrm{~b}_{3}\right.$, $\mathrm{b}_{4}, \mathrm{~b}_{5}, \mathrm{~b}_{6}, \mathrm{~b}_{7}, \mathrm{~b}_{9}, \mathrm{y}_{1}, \mathrm{y}_{2}, \mathrm{y}_{3}, \mathrm{y}_{4}, \mathrm{y}_{5}, \mathrm{y}_{6}, \mathrm{y}_{7}, \mathrm{y}_{8}, \mathrm{y}_{9}, \mathrm{y}_{10}, \mathrm{y}_{11}, \mathrm{y}_{12}$, and $\mathrm{y}_{13}$ ). The ubiquitination site was localized at residue $\mathrm{K}_{439}$ in vimentin amino acid sequence, and its ubiquitination level was significantly decreased with a ratio of $\mathrm{T} / \mathrm{N}$ (tumor/control) $=0.36$ in LSCCs compared to controls (Supplemental Table 1). There is another representative MS/MS spectrum of ${ }^{633} \mathrm{RPVK}^{*}$ DGGGTNSITVR ${ }^{647}$ (precursor ion $[\mathrm{M}+3 \mathrm{H}]^{3+}$ $m / z=557.6365, \mathrm{RT}=15.86 \mathrm{~min}$, and $\mathrm{K}^{*}=$ ubiquitinated lysine residue) from MRP1 (P33527) (Fig. 1b), with high S/N ratio and excellent $b$-ion and $y$-ion series $\left(b_{1}, b_{2}, b_{3}, b_{4}, b_{5}, b_{6}\right.$, $\mathrm{b}_{7}, \mathrm{~b}_{8}, \mathrm{~b}_{9}, \mathrm{y}_{1}, \mathrm{y}_{2}, \mathrm{y}_{3}, \mathrm{y}_{4}, \mathrm{y}_{5}, \mathrm{y}_{6}, \mathrm{y}_{7}, \mathrm{y}_{8}, \mathrm{y}_{9}, \mathrm{y}_{10}$, and $\left.\mathrm{y}_{11}\right)$. The ubiquitination site was localized at residue $\mathrm{K}_{636}$ in MRP1 amino acid sequence, and its ubiquitination level was significantly increased in LSCCs compared to controls (Supplemental Table 1). Totally, 125 (31.25\%) of 400 DUPs were found to have two or more identified ubiquitination sites. Among 654 ubiquitination sites, the ubiquitination levels of 104 sites were significantly increased and 131 were significantly decreased in LSCCs compared to controls, 346 ubiquitination sites were only quantitatively detected in LSCCs but not in controls, and 73 ubiquitination sites were only quantitatively detected in controls but not in LSCCs (Supplemental Table 1). Thus, totally, $450(104+346)$ ubiquitination sites showed increased ubiquitination levels in LSCCs, and $207(131+73)$ ubiquitination sites showed decreased ubiquitination levels in LSCCs.

\section{Ubiquitination motifs occurred in LSCC}

Motif-X analysis revealed statistically significant ubiquitination motifs that were prone to be ubiquitinated in LSCC, based on those identified 654 ubiquitination sites in LSCC tissues. The results found that motifs A-X-K*, A-XX$\mathrm{K}^{*}$, and $\mathrm{A}-\mathrm{XXX}-\mathrm{K}^{*}\left(\mathrm{X}=\right.$ any amino acid residue, $\mathrm{K}^{*}$ was the lysine residue that is prone to be ubiquitinated) were significantly prone to be ubiquitinated (Fig. 2). Of them, A-XX-K* was the most significant motif determined with 113 (113/ $654=17.3 \%$ ) ubiquitination sites. The other two motifs A$\mathrm{X}-\mathrm{K}$ and A-XXX-K were determined with $93(93 / 654=$ $14.2 \%)$ and $82(82 / 654=12.5 \%)$ ubiquitination sites, respectively. The ubiquitination motifs A-X $(1 / 2 / 3)-\mathrm{K}^{*}$ showing alanine residue $(\mathrm{A})$ in the upstream of the ubiquitination site $\left(\mathrm{K}^{*}\right)$ had a certain influence on the occurrence of ubiquitination at $\mathrm{K}$ residue, but no amino acid residue in the downstream of the ubiquitination site $\left(\mathrm{K}^{*}\right)$ was found to be meaningful for the occurrence of ubiquitination at $\mathrm{K}$ residue.

\section{Functional characteristics of DUPs in LSCC}

GO enrichment analysis of 400 DUPs revealed 10 statistically significant functional clusters to comprehensively reflect the functional characteristics of DUPs in LSCC [42]. Comprehensive analysis of these functional clusters found those DUPs were involved in many cancer-related biological functions, such as cell-cell adhesion in cluster 1, regulation of the assemble of proteasome complex and UPS in clusters 2 and 3, transcriptional and translational regulations in cluster 6 , cell signal transduction in cluster 2 , and anti-tumor drug metabolism in cluster 8 (Table 2). 


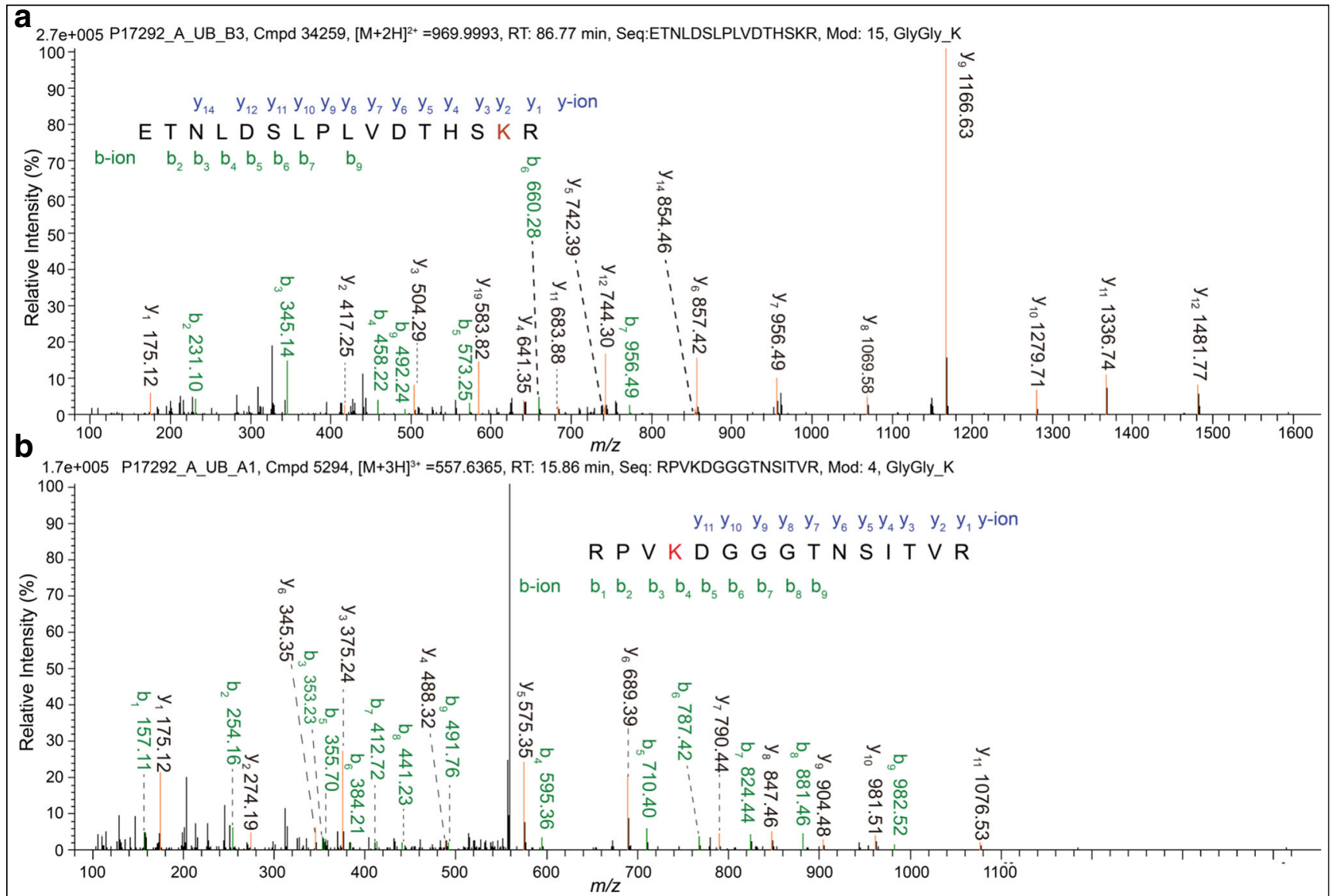

Fig. 1 Representative MS/MS spectra of ubiquitinated peptides: ${ }^{425}$ ETNLDSLPLVDTHSK* ${ }^{440}$ from vimentin (P08670) (a) and ${ }^{633}{ }^{\text {RPVK*DGGGTNSITVR }}{ }^{647}$ from multidrug resistance-associated protein 1 (MRP1) (P33527) (b). K* = ubiquitinated lysine residue

\section{Ubiquitination-involved molecular network alternations in LSCC}

KEGG pathway network analysis of 400 DUPs revealed 39 significant KEGG pathways $(p<0.05$ and FDR $<0.05$ ) (Fig. 3, Supplemental Table 2). Comprehensive analysis of all pathways demonstrated that DUPs were mainly enriched in four important tumor-related molecular network systems, including the UPS, cell energy metabolism, cell-cell adhesion, and cell signal transduction. Insights into these ubiquitination-involved molecular network changes might reveal the roles of ubiquitination in the carcinogenesis process of LSCC.

Ubiquitin-proteasome system The proteasome is a pivotal component of UPS for ubiquitin-mediated proteolysis. The $26 \mathrm{~S}$ proteasome is a complex, including two 19S regulatory particles (PA700) and one 20S core particle. This study discovered three DUPs (Rpn3, Rpn5, and Rpn6) in PA700 (Lid) and seven DUPs (Rpn13, Rpt1-Rpt6) in PA700 (Base). Their ubiquitination levels were significantly increased at residues $\mathrm{K}_{34}($ ratio $\mathrm{T} / \mathrm{N}=2.27)$ in $\mathrm{Rpn} 13 ; \mathrm{K}_{293}(\mathrm{~T}+\mathrm{N}-)$ in $\mathrm{Rpt} 2 ; \mathrm{K}_{46}$ (ratio $\mathrm{T} / \mathrm{N}=4.96)$ in Rpt1; $\mathrm{K}_{372}(\mathrm{~T}+\mathrm{N}-)$ in $\mathrm{Rpt5} ; \mathrm{K}_{273}(\mathrm{~T}+/ \mathrm{N}$
-) in Rpt4; $\mathrm{K}_{346}(\mathrm{~T}+/ \mathrm{N}-), \mathrm{K}_{330}(\mathrm{~T}+/ \mathrm{N}-)$, and $\mathrm{K}_{290}(\mathrm{~T}+/ \mathrm{N}-)$ in Rpt6; $\mathrm{K}_{194}(\mathrm{~T}+\mathrm{N}-), \mathrm{K}_{328}(\mathrm{~T}+/ \mathrm{N}-)$, and $\mathrm{K}_{62}($ ratio $\mathrm{T} / \mathrm{N}=2.37)$ in Rpt4; $\mathrm{K}_{273}(\mathrm{~T}+\mathrm{N}-)$ in $\mathrm{Rpn} 3 ; \mathrm{K}_{32}(\mathrm{~T}+\mathrm{N}-)$ in Rpn6; and $\mathrm{K}_{147}(\mathrm{~T}+\mathrm{N}-)$ in Rpn5. The ubiquitination level was significantly decreased at residue $\mathrm{K}_{53}($ ratio $\mathrm{T} / \mathrm{N}=0.33)$ in $\mathrm{Rpt5}$ (Supplemental Fig. 1.1).

Cell energy metabolism Abnormal ubiquitinations in cell energy metabolism-related pathways might contribute to tumor metabolic reprogramming that is a hallmark of cancer. KEGG pathway analysis revealed that DUPs were involved in cell energy metabolism, including glycolysis/gluconeogenesis, carbon metabolism, central carbon metabolism, and fructose and mannose metabolism in cancer. In addition, most DUPs (HK1, GAPDH, ALDOA, ENO1, and PGK1) in HIF-1 signaling pathway were involved in glucose metabolism; thus, HIF-1 signaling pathway was also classified into cell energy metabolism (Supplemental Fig. 1.6). For glycolysis pathway, all 12 ubiquitination sites within 8 DUPs (including PKM, $\mathrm{P} 14618$, a rate-limiting enzyme) had the significantly increased ubiquitination levels; of these, ubiquitination at residue K270 in PKM was only detected in LSCC tissues, which indicated that ubiquitination might affect glycolysis 
a
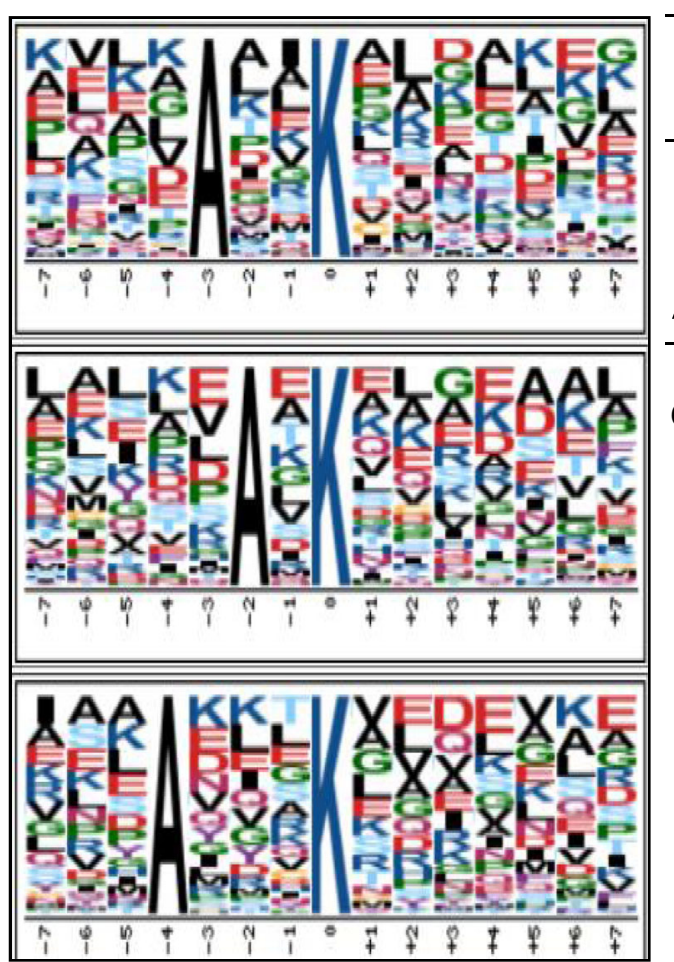

b

\begin{tabular}{cccccccc}
\hline Motif & Motif & \multicolumn{1}{c}{ Foreground Foreground Background Background } & Fold & Pore \\
score & Matches & Size & Matches & Size & Increase & P Value \\
\hline AXXK & 6.14 & 113 & 1101 & 45331 & 709129 & 1.61 & $<0.0001$ \\
AXK & 4.55 & 93 & 988 & 40411 & 663798 & 1.55 & $<0.0001$ \\
AXXXK & 4.12 & 82 & 895 & 36848 & 623387 & 1.55 & $<0.0001$ \\
\hline
\end{tabular}

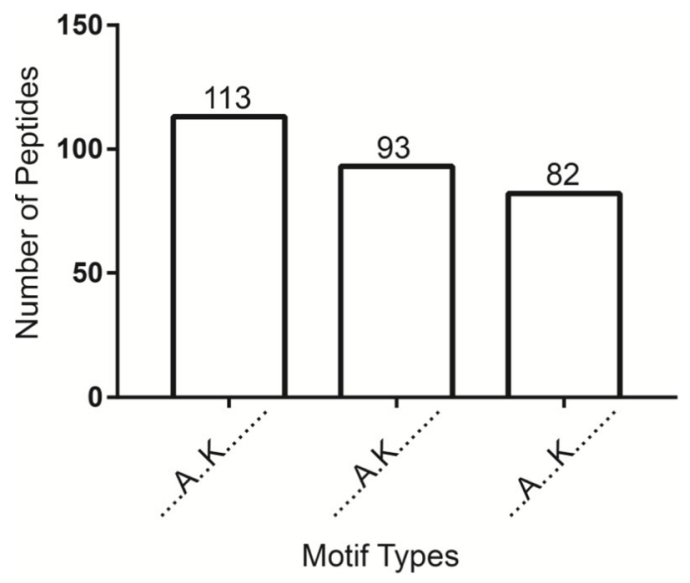

Fig. 2 Ubiquitination motifs occurred in human LSCCs. a Potential ubiquitin recognition motif logos (AXXK, AXK, and AXXXK) in human LSCCs. b The statistically significant A-X (1/2/3)-K* motifs in LSCCs. $\mathbf{c}$ The number of ubiquitinated peptides among three motif types

(Supplemental Fig. 1.2). For fructose and mannose metabolism pathway, this study identified four DUPs, whose ubiquitination levels were significantly increased at residues $\mathrm{K}_{111}($ ratio $\mathrm{T} / \mathrm{N}=3.84)$ and $\mathrm{K}_{200}($ ratio $\mathrm{T} / \mathrm{N}=3.8)$ in $\mathrm{P} 04075$; $\mathrm{K}_{117}(\mathrm{~T}+/ \mathrm{N}-), \mathrm{K}_{186}($ ratio $\mathrm{T} / \mathrm{N}=16.91), \mathrm{K}_{194}($ ratio $\mathrm{T} / \mathrm{N}=$ 2.67), and $\mathrm{K}_{215}$ (ratio $\left.\mathrm{T} / \mathrm{N}=3.22\right)$ in $\mathrm{P} 04406 ; \mathrm{K}_{97}(\mathrm{~T}+\mathrm{N}-$ ) in B3KXY9; and $\mathrm{K}_{168}(\mathrm{~T}+\mathrm{N}-)$ in P60174 (Supplemental Fig. 1.3). For central carbon metabolism of cancer pathway, this study identified six DUPs, whose ubiquitination levels were significantly increased at $\mathrm{K}_{97}(\mathrm{~T}+/ \mathrm{N}-)$ in $\mathrm{B} 3 \mathrm{KXY} 9$, $\mathrm{K}_{270}(\mathrm{~T}+/ \mathrm{N}-)$ in $\mathrm{P} 14618, \mathrm{~K}_{178}(\mathrm{~T}+\mathrm{N}-)$ and $\mathrm{K}_{362}$ (ratio $\mathrm{T} / \mathrm{N}=7.19)$ in $\mathrm{Q} 15758, \mathrm{~K}_{270}($ ratio $\mathrm{T} / \mathrm{N}=110.93)$ and $\mathrm{K}_{502}$ $(\mathrm{T}+\mathrm{N}-)$ in $\mathrm{Q} 59 \mathrm{GX} 2, \mathrm{~K}_{19}(\mathrm{~T}+/ \mathrm{N}-)$ in $\mathrm{Q} 01650$, and $\mathrm{K}_{431}$ $(\mathrm{T}+\mathrm{N}-)$ in A0A024R8U1 (Supplemental Fig. 1.4). For carbon metabolism pathway, this study identified 10 DUPs, whose ubiquitination levels were significantly increased at $\mathrm{K}_{380}(\mathrm{~T}+/ \mathrm{N}-)$ and $\mathrm{K}_{57}(\mathrm{~T}+/ \mathrm{N}-)$ in $\mathrm{O} 43175 ; \mathrm{K}_{59}$ (ratio $\mathrm{T} / \mathrm{N}=2.66)$ and $\mathrm{K}_{377}$ (ratio $\left.\mathrm{T} / \mathrm{N}=16.52\right)$ in $\mathrm{P} 52209 ; \mathrm{K}_{130}$ $(\mathrm{T}+/ \mathrm{N}-)$ in A0A140VK56; $\mathrm{K}_{81}(\mathrm{~T}+/ \mathrm{N}-)$ in A0A24R4F1; $\mathrm{K}_{111}$ (ratio T/N = 3.84) and $\mathrm{K}_{200}($ ratio $\mathrm{T} / \mathrm{N}=3.8$ ) in $\mathrm{P} 04075$; $\mathrm{K}_{117}(\mathrm{~T}+\mathrm{N}-), \mathrm{K}_{215}($ ratio $\mathrm{T} / \mathrm{N}=3.22), \mathrm{K}_{194}($ ratio $\mathrm{T} / \mathrm{N}=$ 2.67), and $\mathrm{K}_{186}$ (ratio $\mathrm{T} / \mathrm{N}=16.91$ ) in $\mathrm{P} 04406 ; \mathrm{K}_{97}(\mathrm{~T}+\mathrm{N}-$ ) in $\mathrm{B} 3 \mathrm{KXY} 9 ; \mathrm{K}_{216}(\mathrm{~T}+/ \mathrm{N}-)$ in $\mathrm{P} 00558 ; \mathrm{K}_{270}(\mathrm{~T}+/ \mathrm{N}-)$ in $\mathrm{P} 14618$; and $\mathrm{K}_{168}(\mathrm{~T}+/ \mathrm{N}-)$ in $\mathrm{P} 60174$ (Supplemental Fig. 1.5). For carbon metabolism pathway, this study identified eight DUPs, whose ubiquitination levels were significantly increased at $\mathrm{K}_{299}(\mathrm{~T}+/ \mathrm{N}-)$ in A0A0S2Z3S6; $\mathrm{K}_{502}(\mathrm{~T}+/ \mathrm{N}-)$ and $\mathrm{K}_{270}($ ratio $\mathrm{T} / \mathrm{N}=110.93)$ in $\mathrm{Q} 59 \mathrm{GX} 2$; $\mathrm{K}_{97}(\mathrm{~T}+/ \mathrm{N}-)$ in B3KXY9; $\mathrm{K}_{1033}(\mathrm{~T}+\mathrm{N}-)$ in $\mathrm{P} 08069 ; \mathrm{K}_{117}$ $(\mathrm{T}+\mathrm{N}-), \mathrm{K}_{215}($ ratio $\mathrm{T} / \mathrm{N}=3.22), \mathrm{K}_{194}($ ratio $\mathrm{T} / \mathrm{N}=2.67)$, and $\mathrm{K}_{186}($ ratio $\mathrm{T} / \mathrm{N}=16.91)$ in $\mathrm{P} 04406 ; \mathrm{K}_{81}(\mathrm{~T}+\mathrm{N}-)$ in A0A024RF1; $\mathrm{K}_{111}$ (ratio $\mathrm{T} / \mathrm{N}=3.84$ ) and $\mathrm{K}_{200}($ ratio $\mathrm{T} / \mathrm{N}=$ 3.8) in $\mathrm{P} 04075$; and $\mathrm{K}_{216}(\mathrm{~T}+\mathrm{N}-)$ in $\mathrm{P} 00558$ (Supplemental Fig. 1.6).

Cell-cell adhesion Epithelial cell adhesion-associated pathways included tight junction and adherens junction, which participated in sustaining cell polarity and regulating cell proliferation and differentiation. For tight junction pathway, this study found that ubiquitination levels were significantly increased at residues $\mathrm{K}_{304}(\mathrm{~T}+\mathrm{N}-), \mathrm{K}_{338}($ ratio $\mathrm{T} / \mathrm{N}=9.37)$, $\mathrm{K}_{336}\left(\right.$ ratio $\mathrm{T} / \mathrm{N}=21.89$ ), $\mathrm{K}_{326}($ ratio $\mathrm{T} / \mathrm{N}=5.07), \mathrm{K}_{96}$ (ratio $\mathrm{T} / \mathrm{N}=4.74)$, and $\mathrm{K}_{60}($ ratio $\mathrm{T} / \mathrm{N}=4.98)$ in tuba; $\mathrm{K}_{794}(\mathrm{~T}+\mathrm{N}-)$ in integrin; $\mathrm{K}_{13}(\mathrm{~T}+\mathrm{N}-)$ in PCNA; $\mathrm{K}_{62}(\mathrm{~T}+/ \mathrm{N}-)$ in PP2A (A0A140VJT0); $\mathrm{K}_{312}(\mathrm{~T}+/ \mathrm{N}-)$ in actin $4 ; \mathrm{K}_{380}(\mathrm{~T}+/ \mathrm{N}-)$ in myosin (A0A024QZJ4); and $\mathrm{K}_{679}(\mathrm{~T}+/ \mathrm{N}-), \mathrm{K}_{1410}(\mathrm{~T}+/ \mathrm{N}-)$, and $\mathrm{K}_{972}$ (ratio $\left.\mathrm{T} / \mathrm{N}=5.40\right)$ in myosin $(\mathrm{A} 0 \mathrm{~A} 024 \mathrm{R} 1 \mathrm{~N} 1)$ and were significantly decreased at residues $\mathrm{K}_{151}(\mathrm{~T}-\mathrm{N}+), \mathrm{K}_{360}$ (ratio $\mathrm{T} / \mathrm{N}=0.09$ ), and $\mathrm{K}_{162}$ (ratio $\mathrm{T} / \mathrm{N}=0.14$ ) in $\mathrm{ERM} ; \mathrm{K}_{620}$ (ratio $\mathrm{T} / \mathrm{N}=0.41)$ in myosin $(\mathrm{P} 35580) ; \mathrm{K}_{135}($ ratio $\mathrm{T} / \mathrm{N}=0.32)$ in RhoA; $\mathrm{K}_{21}$ (ratio T/N = 0.48) in PP2A (A0A140VJS0); and $\mathrm{K}_{257}($ ratio $\mathrm{T} / \mathrm{N}=0.05)$ and $\mathrm{K}_{239}(\mathrm{~T}-/ \mathrm{N}+)$ in claudin 
Table 2 The functional categories of 400 DUPs identified with $\mathrm{GO}$ analysis

\begin{tabular}{|c|c|c|}
\hline Category & Term & $p$ value \\
\hline \multicolumn{3}{|l|}{ Annotation cluster 1} \\
\hline $\begin{array}{l}\text { GOTERM_MF_ } \\
\text { DIRECT }\end{array}$ & Cadherin binding involved in cell-cell adhesion & $3.11 \mathrm{E}-18$ \\
\hline GOTERM_CC_DIRECT & Cell-cell adherens junction & $2.24 \mathrm{E}-17$ \\
\hline GOTERM_BP_DIRECT & Cell-cell adhesion & $1.23 \mathrm{E}-13$ \\
\hline \multicolumn{3}{|l|}{ Annotation cluster 2} \\
\hline GOTERM_CC_DIRECT & Proteasome accessory complex & $4.60 \mathrm{E}-12$ \\
\hline GOTERM_BP_DIRECT & $\begin{array}{l}\text { Antigen processing and presentation of exogenous peptide } \\
\text { antigen via MHC class I, TAP-dependent }\end{array}$ & $1.59 \mathrm{E}-11$ \\
\hline GOTERM_BP_DIRECT & Regulation of cellular amino acid metabolic process & $3.49 \mathrm{E}-09$ \\
\hline GOTERM_BP_DIRECT & NIK/NF-kappaB signaling & $5.35 \mathrm{E}-09$ \\
\hline GOTERM_BP_DIRECT & $\begin{array}{l}\text { Negative regulation of ubiquitin-protein ligase activity involved } \\
\text { in mitotic cell cycle }\end{array}$ & $1.27 \mathrm{E}-08$ \\
\hline GOTERM_BP_DIRECT & Stimulatory C-type lectin receptor signaling pathway & $1.85 \mathrm{E}-08$ \\
\hline GOTERM_BP_DIRECT & $\begin{array}{l}\text { Positive regulation of ubiquitin-protein ligase activity involved } \\
\text { in regulation of mitotic cell cycle transition }\end{array}$ & 2.83E-08 \\
\hline GOTERM_BP_DIRECT & Anaphase-promoting complex-dependent catabolic process & $4.43 \mathrm{E}-08$ \\
\hline GOTERM_BP_DIRECT & Tumor necrosis factor-mediated signaling pathway & 8.37E-08 \\
\hline GOTERM_BP_DIRECT & Positive regulation of canonical Wnt signaling pathway & $1.04 \mathrm{E}-07$ \\
\hline GOTERM_BP_DIRECT & $\mathrm{T}$ cell receptor signaling pathway & $2.37 \mathrm{E}-07$ \\
\hline GOTERM_BP_DIRECT & Fc-epsilon receptor signaling pathway & $4.90 \mathrm{E}-07$ \\
\hline GOTERM_BP_DIRECT & Protein polyubiquitination & $7.65 \mathrm{E}-07$ \\
\hline GOTERM_BP_DIRECT & Negative regulation of canonical Wnt signaling pathway & 4.36E-06 \\
\hline \multicolumn{3}{|l|}{ Annotation cluster 3} \\
\hline GOTERM_CC_DIRECT & Proteasome regulatory particle, base subcomplex & $4.88 \mathrm{E}-10$ \\
\hline GOTERM_CC_DIRECT & Nuclear proteasome complex & $1.00 \mathrm{E}-09$ \\
\hline GOTERM_CC_DIRECT & Cytosolic proteasome complex & $7.28 \mathrm{E}-09$ \\
\hline $\begin{array}{l}\text { GOTERM_MF } \\
\text { DIRECT }\end{array}$ & Proteasome-activating ATPase activity & $1.54 \mathrm{E}-08$ \\
\hline GOTERM_BP_DIRECT & $\begin{array}{l}\text { Positive regulation of RNA polymerase II transcriptional } \\
\text { preinitiation complex assembly }\end{array}$ & $3.41 \mathrm{E}-07$ \\
\hline $\begin{array}{l}\text { GOTERM_MF } \\
\text { DIRECT }\end{array}$ & TBP-class protein binding & $2.10 \mathrm{E}-06$ \\
\hline GOTERM_BP_DIRECT & Positive regulation of proteasomal protein catabolic process & $1.05 \mathrm{E}-05$ \\
\hline GOTERM_BP_DIRECT & Protein catabolic process & $1.41 \mathrm{E}-04$ \\
\hline \multicolumn{3}{|l|}{ Annotation cluster 4} \\
\hline GOTERM_BP_DIRECT & Regulation of ventricular cardiac muscle cell action potential & $1.11 \mathrm{E}-03$ \\
\hline $\begin{array}{l}\text { GOTERM_MF_- } \\
\text { DIRECT }\end{array}$ & $\begin{array}{l}\text { Cell-adhesive protein binding involved in bundle of His } \\
\text { cell-Purkinje myocyte communication }\end{array}$ & $5.30 \mathrm{E}-03$ \\
\hline \multicolumn{3}{|l|}{ Annotation cluster 5} \\
\hline GOTERM_CC_DIRECT & Haptoglobin-hemoglobin complex & $2.43 \mathrm{E}-05$ \\
\hline GOTERM_CC_DIRECT & Endocytic vesicle lumen & $1.71 \mathrm{E}-04$ \\
\hline $\begin{array}{l}\text { GOTERM_MF_- } \\
\text { DIRECT }\end{array}$ & Haptoglobin binding & $1.10 \mathrm{E}-03$ \\
\hline GOTERM_BP_DIRECT & Positive regulation of cell death & $1.90 \mathrm{E}-02$ \\
\hline GOTERM_CC_DIRECT & Hemoglobin complex & $1.97 \mathrm{E}-02$ \\
\hline $\begin{array}{l}\text { GOTERM_MF_ } \\
\text { DIRECT }\end{array}$ & Oxygen transporter activity & $2.90 \mathrm{E}-02$ \\
\hline GOTERM_BP_DIRECT & Oxygen transport & $3.43 \mathrm{E}-02$ \\
\hline \multicolumn{3}{|l|}{ Annotation cluster 6} \\
\hline GOTERM_BP_DIRECT & SRP-dependent cotranslational protein targeting to membrane & $9.85 \mathrm{E}-05$ \\
\hline GOTERM_BP_DIRECT & $\begin{array}{l}\text { Nuclear-transcribed mRNA catabolic process, } \\
\text { nonsense-mediated decay }\end{array}$ & $5.83 \mathrm{E}-04$ \\
\hline GOTERM_BP_DIRECT & Viral transcription & $1.69 \mathrm{E}-03$ \\
\hline
\end{tabular}


Table 2 (continued)

\begin{tabular}{llr}
\hline Category & Term & $p$ value \\
\hline GOTERM_BP_DIRECT & Translational initiation & $5.82 \mathrm{E}-03$ \\
GOTERM_CC_DIRECT & Ribosome & $3.40 \mathrm{E}-02$ \\
Annotation cluster 7 & & \\
GOTERM_MF_ & Voltage-gated anion channel activity & $5.30 \mathrm{E}-03$ \\
DIRECT & Porin activity & $5.30 \mathrm{E}-03$ \\
GOTERM_MF_ & \\
DIRECT & Pore complex & $1.11 \mathrm{E}-02$ \\
GOTERM_CC_DIRECT & $3.02 \mathrm{E}-02$ \\
GOTERM_BP_DIRECT & Anion transport & $4.34 \mathrm{E}-02$ \\
GOTERM_BP_DIRECT & Regulation of anion transmembrane transport \\
Annotation cluster 8 & & $1.00 \mathrm{E}-02$ \\
GOTERM_BP_DIRECT & Daunorubicin metabolic process & $1.00 \mathrm{E}-02$ \\
GOTERM_BP_DIRECT & Doxorubicin metabolic process & \\
Annotation cluster 9 & & $1.00 \mathrm{E}-02$ \\
GOTERM_BP_DIRECT & Nucleotide-excision repair, DNA damage recognition \\
GOTERM_BP_DIRECT & Global genome nucleotide-excision repair & $2.47 \mathrm{E}-02$ \\
Annotation cluster 10 & & \\
GOTERM_MF_ & Neutral amino acid transmembrane transporter activity & $1.82 \mathrm{E}-02$ \\
DIRECT & & $2.62 \mathrm{E}-02$ \\
GOTERM_BP_DIRECT & Neutral amino acid transport & \\
\hline
\end{tabular}

(Supplemental Fig. 1.7). For the adherens junction pathway, this study found that ubiquitination levels were significantly increased at residues $\mathrm{K}_{312}(\mathrm{~T}+\mathrm{N}-)$ in A0A024R694; $\mathrm{K}_{1033}$ $(\mathrm{T}+\mathrm{N}-)$ in $\mathrm{P} 08069 ; \mathrm{K}_{935}(\mathrm{~T}+/ \mathrm{N}-)$ in A0A024RC65; $\mathrm{K}_{119}$ $(\mathrm{T}+/ \mathrm{N}-)$ in A0A024R324; $\mathrm{K}_{749}(\mathrm{~T}+/ \mathrm{N}-), \mathrm{K}_{676}(\mathrm{~T}+\mathrm{N}-)$, $\mathrm{K}_{810}\left(\mathrm{~T}+/ \mathrm{N}-\right.$ ), and $\mathrm{K}_{355}$ (ratio $\mathrm{T} / \mathrm{N}=4.99$ ) in $\mathrm{O} 60716$; and $\mathrm{K}_{147}(\mathrm{~T}+/ \mathrm{N}-)$ in A0A024R1P2 and were significantly decreased at residues $\mathrm{K}_{161}$ (ratio $\mathrm{T} / \mathrm{N}=0.2$ ) in A0A024RC65 and $\mathrm{K}_{135}$ (ratio $\mathrm{T} / \mathrm{N}=0.32$ ) in A0A024R324 (Supplemental Fig. 1.8).

Cell signal transduction Cell signal transduction pathways included PI3K-AKT, RAP1, and cGMP-PKG signaling pathways. For the PI3K-AKT pathway, 13 DUPs were identified, and the ubiquitination levels were significantly increased at residues $\mathrm{K}_{1033}(\mathrm{~T}+/ \mathrm{N}-)$ in IGFIR, $\mathrm{K}_{62}(\mathrm{~T}+\mathrm{N}-)$ in PP2A (A0A140VJT0), $\mathrm{K}_{517}(\mathrm{~T}+\mathrm{N}-)$ and $\mathrm{K}_{587}(\mathrm{~T}+\mathrm{N}-)$ in $\mathrm{SYK}$, $\mathrm{K}_{95}(\mathrm{~T}+/ \mathrm{N}-)$ and $\mathrm{K}_{624}(\mathrm{~T}+/ \mathrm{N}-)$ in HSP90, $\mathrm{K}_{617}(\mathrm{~T}+/ \mathrm{N}-)$ in EPHA2, and $\mathrm{K}_{794}(\mathrm{~T}+\mathrm{N}-)$ in ITGB1 and were significantly decreased at residues $\mathrm{K}_{23}$ (ratio $\left.\mathrm{T} / \mathrm{N}=0.15\right)$ in $\mathrm{GNB} 2, \mathrm{~K}_{23}$ (ratio $\mathrm{T} / \mathrm{N}=0.12$ ) in $\mathrm{GNB} 1, \mathrm{~K}_{34}\left(\mathrm{~T}-\mathrm{N}+\right.$ ) in $\mathrm{GNG} 12, \mathrm{~K}_{21}$ (ratio $\mathrm{T} / \mathrm{N}=0.48$ ) in $\mathrm{PP} 2 \mathrm{~A}$ (A0A140VJS0), $\mathrm{K}_{106}$ (ratio $\mathrm{T} / \mathrm{N}=0.43)$ in $14-3-3, \mathrm{~K}_{11}(\mathrm{~T}-\mathrm{N}+)$ in GNB5, and $\mathrm{K}_{957}(\mathrm{~T}$ $-/ \mathrm{N}+$ ) in the extracellular matrix (ECM) (Supplemental Fig. 1.9). For RAP1 signaling pathway, nine DUPs were identified, and the ubiquitination levels were significantly increased at residues $\mathrm{K}_{46}(\mathrm{~T}+/ \mathrm{N}-)$ in $\mathrm{P} 04899 ; \mathrm{K}_{147}(\mathrm{~T}+/ \mathrm{N}-)$ in A0A024R1P2; $\mathrm{K}_{92}(\mathrm{~T}+\mathrm{N}-)$ in $\mathrm{P} 08754 ; \mathrm{K}_{119}(\mathrm{~T}+/ \mathrm{N}-)$ in A0A024R324; $\mathrm{K}_{617}(\mathrm{~T}+/ \mathrm{N}-)$ in A0A024QZA8; $\mathrm{K}_{794}(\mathrm{~T}+/ \mathrm{N}$ $-)$ in $\mathrm{P} 05556 ; \mathrm{K}_{749}(\mathrm{~T}+\mathrm{N}-) ; \mathrm{K}_{676}(\mathrm{~T}+\mathrm{N}-), \mathrm{K}_{406}(\mathrm{~T}+\mathrm{N}-)$,
$\mathrm{K}_{810}(\mathrm{~T}+\mathrm{N}-)$, and $\mathrm{K}_{355}$ (ratio $\left.\mathrm{T} / \mathrm{N}=4.99\right)$ in $\mathrm{O} 60716 ; \mathrm{K}_{91}$ $(\mathrm{T}+\mathrm{N}-)$ in $\mathrm{P} 07737$; and $\mathrm{K}_{1033}(\mathrm{~T}+\mathrm{N}-)$ in $\mathrm{P} 08069$ and were significantly decreased at residues $\mathrm{K}_{135}$ (ratio $\mathrm{T} / \mathrm{N}=0.32$ ) in A0A024R324 (Supplemental Fig. 1.10). For the cGMP-PKG signaling pathway, this study identified eight DUPs, and the ubiquitination levels were significantly increased at residues $\mathrm{K}_{605}(\mathrm{~T}+\mathrm{N}-), \mathrm{K}_{444}(\mathrm{~T}+\mathrm{N}-), \mathrm{K}_{468}($ ratio $\mathrm{T} / \mathrm{N}=22.88), \mathrm{K}_{661}$ $(\mathrm{T}+/ \mathrm{N}-), \mathrm{K}_{212}(\mathrm{~T}+/ \mathrm{N}-)$ in $\mathrm{P} 05023 ; \mathrm{K}_{128}(\mathrm{~T}+/ \mathrm{N}-)$ in A0A0S2Z3L2; $\mathrm{K}_{75}(\mathrm{~T}+\mathrm{N}-)$ in A0A024R968; $\mathrm{K}_{12}(\mathrm{~T}+\mathrm{N}-)$ in $\mathrm{P} 21796 ; \mathrm{K}_{12}(\mathrm{~T}+/ \mathrm{N}-)$ in Q9Y277; $\mathrm{K}_{46}(\mathrm{~T}+/ \mathrm{N}-)$ in P04899; $\mathrm{K}_{92}(\mathrm{~T}+/ \mathrm{N}-)$ in $\mathrm{P} 08754$; and $\mathrm{K}_{119}(\mathrm{~T}+/ \mathrm{N}-)$ in A0A024R324 and were significantly decreased at residue $\mathrm{K}_{135}$ (ratio $\mathrm{T} / \mathrm{N}=$ 0.32) in A0A024R324 (Supplemental Fig. 1.11).

\section{Identification of hub molecules with PPI analysis of DUPs}

All 400 DUPs were input into the STRING software to construct PPI networks. The PPI results were imported into Cytoscape software in combination with ubiquitination intensity change of each DUP. After the isolated and partially connected nodes were removed, a complex network of DUPs was constructed (Fig. 4). The red node represented the increased intensities of all identified ubiquitination sites in one protein, the green node represented the decreased intensities of all identified ubiquitination sites in one protein, and the yellow node indicated at least two ubiquitination sites in a protein with inconsistent ubiquitination intensities. A total of 44 molecules were identified as hub molecules with topology property degrees $\geq 10$, among which $11.4 \%$ (5/44) molecules, 


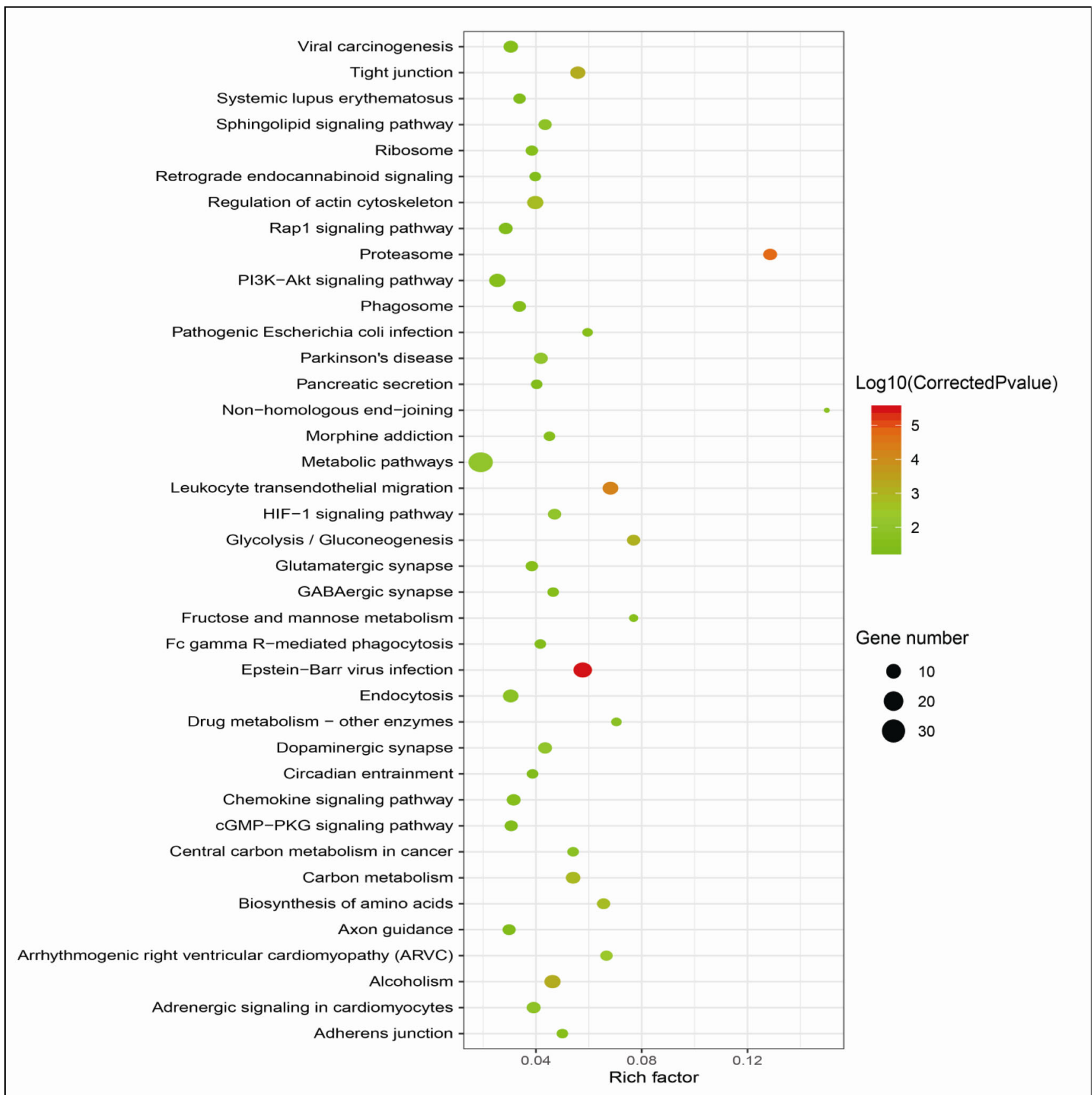

Fig. 3 Ubiquitination-involved pathway-network alterations in human LSCCs. A total of 39 significantly significant enriched pathways $(p<0.05$ and FDR $<0.05)$ were identified. The darker dot means the

including vimentin $(\mathrm{VIM})($ degree $=21)$, ACTC1 $($ degree $=$ 18), YWHAE (degree = 14), ANXA5 (degree = 12), and UBE2N (degree $=11$ ), had the decreased ubiquitination levels; 9.1\% (4/44) molecules, including UBA52 (degree = 43), ATP5B (degree = 19), VCP (degree = 14), and ANXA1 (degree $=10$ ), had at least two ubiquitination sites with inconsistent ubiquitination levels; and the rest of the molecules (35/ $44=79.5 \%$ ) had an average degree of 17.7 and increased ubiquitination levels (Supplemental Table 3). more significant enrichment. The size of the dot represents the number of DUPs enriched in the pathway

\section{Ubiquitination affects LSCC patient's outcome by regulating intracellular abundance of vimentin and MRP1}

Survival analysis of 44 hub molecules was performed based on LSCC RNA-seq and clinical information of 494 LSCC patients from the TCGA database, which identified 18 prognosis-related mRNAs, including MRP1, IGF1R, VIM, ATP5A1, TUBA1B, VDAC1, HSPA8, PCNA, ATP5B, 


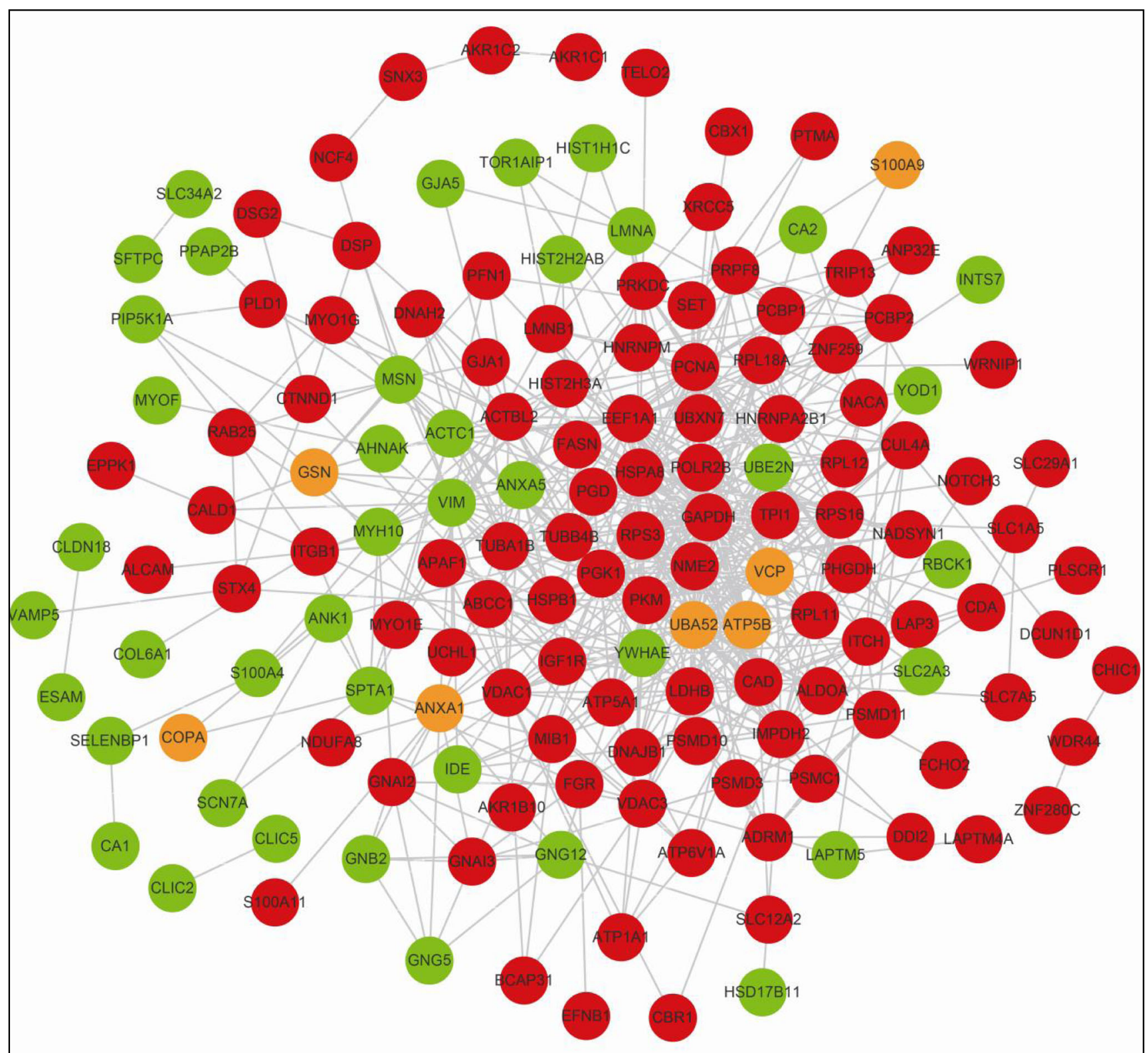

Fig. 4 Protein-protein interaction (PPI) network in human LSCCs. Red node means the increased ubiquitination level in LSCCs. Green node means the decreased ubiquitination level in LSCCs. Yellow node means multiple ubiquitination sites in a protein with reverse (some increased and some decreased) ubiquitination levels in LSCCs
ACTC1, HSPB1, ITCH, ANXA5, UBE2N, UBXN7, VDAC3, PRPF8, and PHGDH (Table 3). The high expressions of seven mRNAs (ATP5A1 and IGF1R in OS; VDAC1, VIM, and PRPF8 in RFS; and ITCH and ANXA5 in both OS and RFS) were associated with poorer survival status, while the high expressions of other nine mRNAs (ACTC1 and UBXN7 in OS; TUBA1B, HSPA8, PCNA, ATP5B, HSPB1, VDAC3, and PHGDH in RFS; and UBE2N and ABCC1 in both OS and RFS) were associated with better survival status (Supplemental Fig. 2).

Because post-transcriptional/translational modifications caused inconsistencies between mRNA and protein levels, further analysis of 18 prognosis-related mRNAs with literature review found that IGF1R, vimentin (VIM encoded), and MRP1 (ABCC1 encoded) were prognosis-related proteins in LSCC [43-45]. For MRP1, its high mRNA expression was associated better survival status (Fig. 5a); however, its high protein expression was associated with poorer survival status [43]. For IGF1R and VIM (vimentin), their high mRNA and protein expressions were all associated with poorer survival status compared to their low expressions (Fig. 5b, c). The abundances of vimentin and MRP1 were increased in the proteasome inhibitor MG132-treated LSCC cell lines (H520 and H226 for vimentin; H226 and Calu-1 for MRP1), indicating 
Table 3 Ubiquitination status of 18 prognosis-related molecules

\begin{tabular}{|c|c|c|c|c|c|}
\hline $\begin{array}{l}\text { UniProt } \\
\text { accession }\end{array}$ & $\begin{array}{l}\text { Gene } \\
\text { symbol }\end{array}$ & Description & $\begin{array}{l}\text { Number of } \\
\text { modified sites }\end{array}$ & Modified peptides & $\begin{array}{l}\text { Ratio } \\
(\mathrm{T} / \mathrm{N})\end{array}$ \\
\hline P25705 & ATP5A1 & ATP synthase subunit alpha & 1 & VGLK*APGIIPR & NA \\
\hline \multirow[t]{6}{*}{ P68363 } & \multirow[t]{6}{*}{ TBA1B } & \multirow[t]{6}{*}{ Tubulin alpha-1B chain } & \multirow[t]{6}{*}{6} & AYHEQLSVAEITNACFEPANQMVK*CDPR & NA \\
\hline & & & & DVNAAIATIK*TKR & 9.37 \\
\hline & & & & DVNAAIATIKTK*R & 21.89 \\
\hline & & & & GDVVPK*DVNAAIATIK & 5.07 \\
\hline & & & & QLFHPEQLITGK*EDAANNYAR & 4.74 \\
\hline & & & & TIGGGDDSFNTFFSETGAGK*HVPR & 4.98 \\
\hline P21796 & VDAC1 & $\begin{array}{l}\text { Voltage-dependent anion-selective } \\
\text { channel protein } 1\end{array}$ & 1 & AVPPTYADLGK*SAR & NA \\
\hline \multirow[t]{7}{*}{ P11142 } & \multirow[t]{7}{*}{ HSPA8 } & \multirow[t]{7}{*}{ Heat shock cognate $71 \mathrm{kDa}$ protein } & \multirow[t]{7}{*}{7} & AMTK*DNNLLGK & NA \\
\hline & & & & CNEIINWLDK*NQTAEKEEFEHQQK & 2.04 \\
\hline & & & & ELEK*VCNPIITK & 6.59 \\
\hline & & & & GTLDPVEK*ALR & NA \\
\hline & & & & LDK*SQIHDIVLVGGSTR & NA \\
\hline & & & & MVQEAEK*YKAEDEK & 2.55 \\
\hline & & & & NQTAEKEEFEHQQK*ELEK & NA \\
\hline P12004 & PCNA & Proliferating cell nuclear antigen & 1 & ILK*CAGNEDIITLR & NA \\
\hline \multirow[t]{9}{*}{ P08670 } & \multirow[t]{9}{*}{ VIM } & \multirow[t]{9}{*}{ Vimentin } & \multirow[t]{9}{*}{9} & ETNLDSLPLVDTHSK*R & 0.36 \\
\hline & & & & FLEQQNK*ILLAELEQLKGQGK & 0.29 \\
\hline & & & & ILLAELEQLK*GQGK & 0.49 \\
\hline & & & & K*LLEGEESR & 0.26 \\
\hline & & & & K*VESLQEEIAFLK & 0.17 \\
\hline & & & & LREK*LQEEMLQR & 0.41 \\
\hline & & & & RQVDQLTNDK*AR & 0.21 \\
\hline & & & & RQVQSLTCEVDALK*GTNESLER & 0.36 \\
\hline & & & & TLLIK*TVETR & 0.26 \\
\hline P06576 & ATP5B & ATP synthase subunit beta & 1 & VLDSGAPIK*IPVGPETLGR & NA \\
\hline P68032 & ACTC1 & Actin, alpha cardiac muscle 1 & 1 & VAPEEHPTLLTEAPLNPK*ANR & 0.46 \\
\hline P04792 & HSPB1 & Heat shock protein beta-1 & 1 & AQLGGPEAAK*SDETAAK & NA \\
\hline P08069 & IGF1R & Insulin-like growth factor 1 receptor & 1 & VAIK*TVNEAASMR & NA \\
\hline \multirow[t]{2}{*}{ Q96J02 } & \multirow[t]{2}{*}{ ITCH } & \multirow{2}{*}{$\begin{array}{l}\text { E3 ubiquitin-protein ligase Itchy } \\
\text { homolog }\end{array}$} & \multirow[t]{2}{*}{2} & FIYGNQDLFATSQSK*EFDPLGPLPPGWEK & 3.05 \\
\hline & & & & VYYVDHVEK*R & NA \\
\hline \multirow[t]{4}{*}{ P08758 } & \multirow[t]{4}{*}{ ANXA5 } & \multirow[t]{4}{*}{ Annexin A5 } & \multirow[t]{4}{*}{4} & GAGTNEK*VLTEIIASR & 0.38 \\
\hline & & & & HALK*GAGTNEK & 0.44 \\
\hline & & & & LIVALMK*PSR & NA \\
\hline & & & & LYDAYELK*HALK & 0.17 \\
\hline \multirow[t]{2}{*}{ P61088 } & \multirow[t]{2}{*}{ UBE2N } & \multirow[t]{2}{*}{ Ubiquitin-conjugating enzyme E2 N } & 2 & DK*WSPALQIR & 0.14 \\
\hline & & & & ICLDILK*DK & 0.26 \\
\hline O94888 & UBXN7 & UBX domain-containing protein 7 & 1 & DVWSNEAVK*NIIR & NA \\
\hline Q9Y277 & VDAC3 & $\begin{array}{l}\text { Voltage-dependent anion-selective } \\
\text { channel protein } 3\end{array}$ & 1 & CNTPTYCDLGK*AAK & NA \\
\hline Q6P2Q9 & PRPF8 & Pre-mRNA-processing-splicing factor 8 & 2 & DLILADYGKK* & NA \\
\hline & & & & DLILADYGK*K & NA \\
\hline O43175 & PHGDH & D-3-phosphoglycerate dehydrogenase & 2 & NAGNCLSPAVIVGLLK*EASK & NA \\
\hline & & & & SATK*VTADVINAAEK & NA \\
\hline P33527 & $\mathrm{ABCC} 1$ & Multidrug resistance-associated protein & 3 & RPVK*DGGGTNSITVR & NA \\
\hline & & 1 & & TYQVAHMKSK* & NA \\
\hline & & & & TYQVAHMK*SK & NA \\
\hline
\end{tabular}




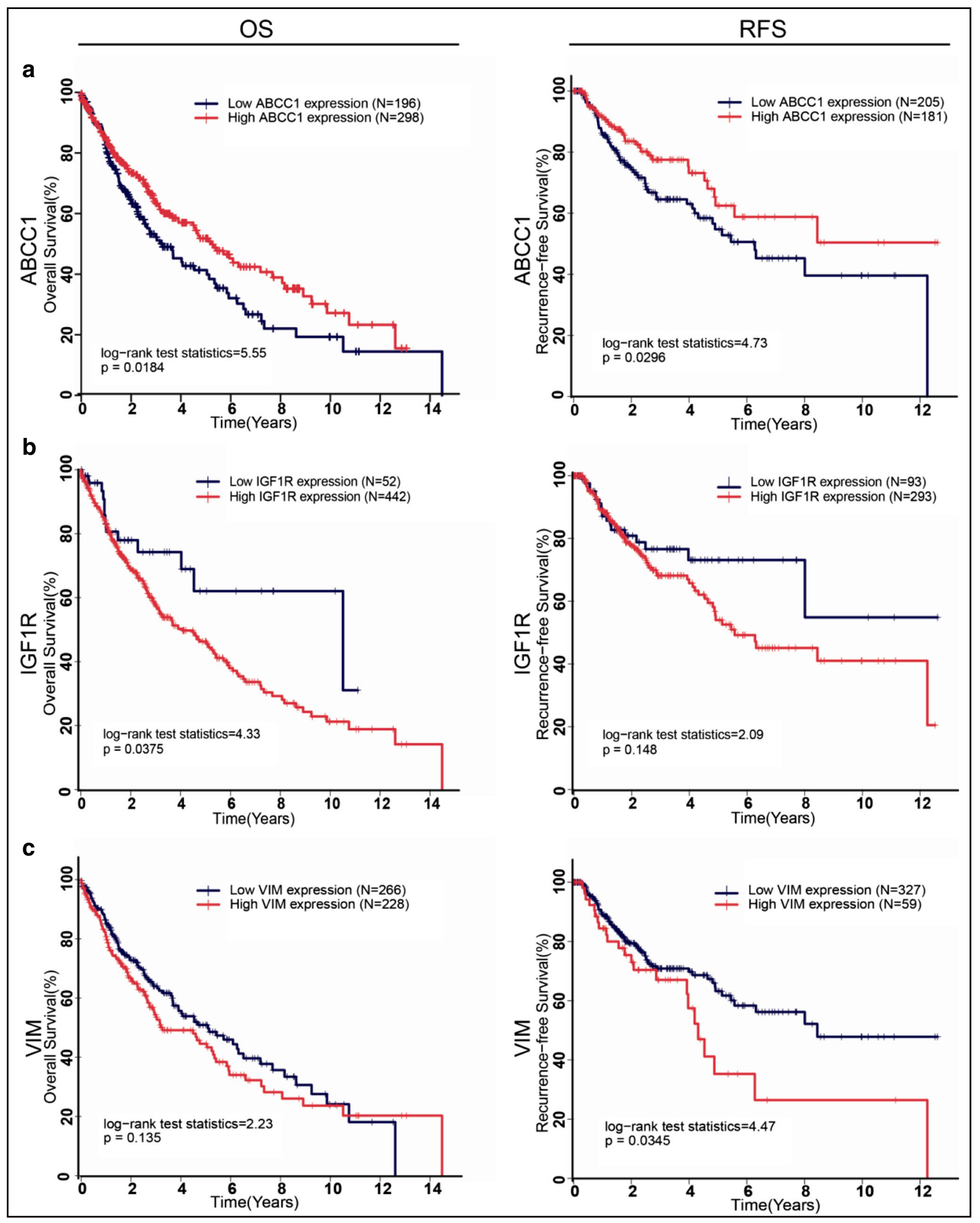

Fig. 5 Survival analysis of ABCC1, IGF1R, and VIM in human LSCCs. a $\mathrm{ABCC} 1$ had significant prognostic value in both overall survival (OS) rate and recurrence free survival (RFS) rate. b IGF1R had significant

prognostic value in OS rate but not in RFS rate. c VIM had significant prognostic value in RFS rate but not in OS rate 


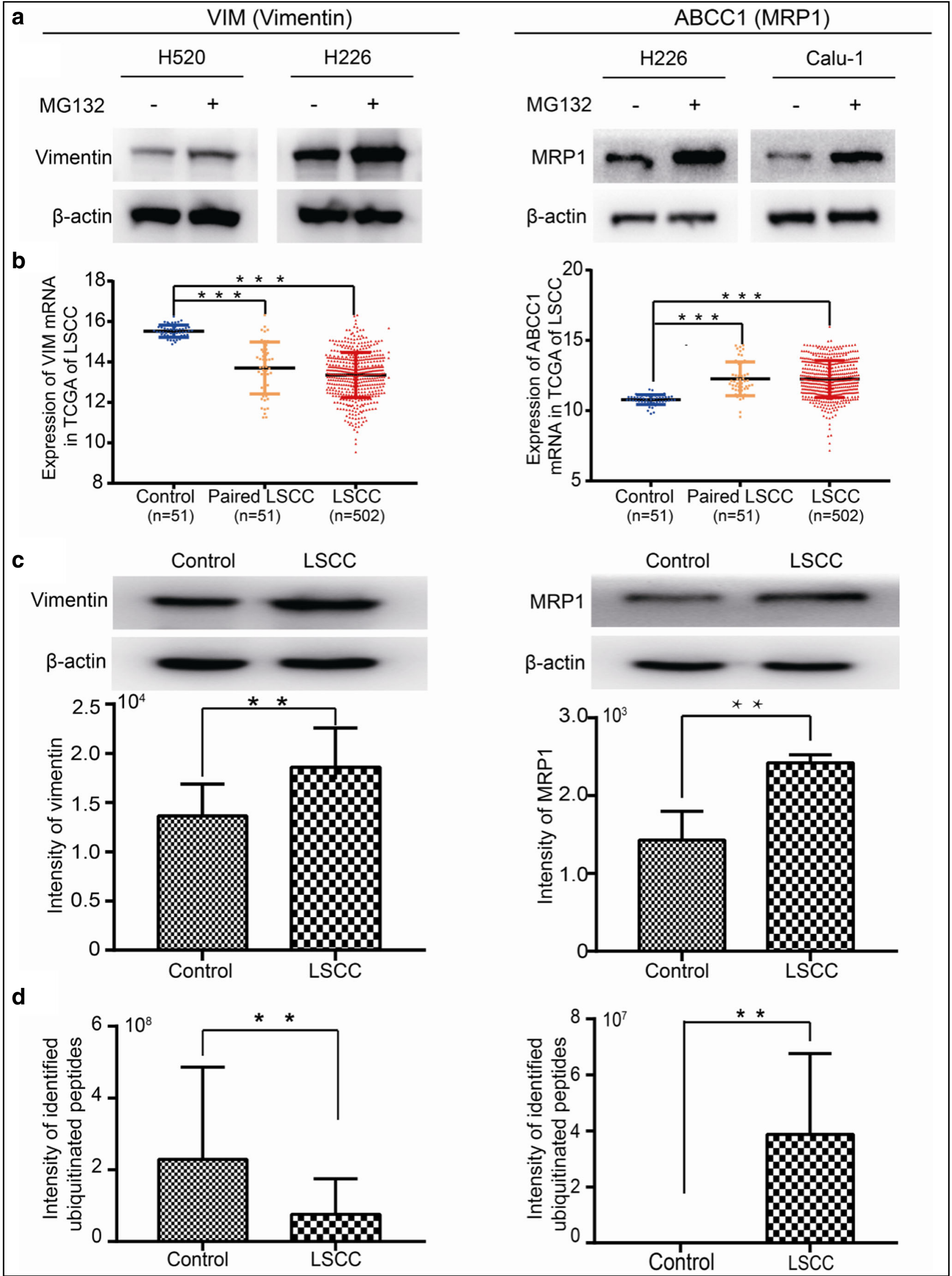


Fig. 6 Comprehensive analysis of vimentin and MRP1 in human LSCCs. a Proteasome inhibitor MG-132 induced the increase of vimentin in LSCC cell lines H520 and H226, and MRP1 in H226 and calu-1. b In the TCGA database, the expression of VIM mRNA was downregulated in 502 LSCC tissues (LSCC) compared with 51 adjacent lung tissue samples (control). VIM expression was also decreased in 51 paired LSCC tissues (paired LSCC) and their adjacent lung tissue samples (control), while the expression of ABCC1 was upregulated in 502 LSCC tissues (LSCC) compared with 51 adjacent lung tissue samples (control). $\mathrm{ABCC} 1$ expression was also increased in 51 paired LSCC tissues (paired LSCC) and their adjacent lung tissue samples (control). c Western blotting showed both vimentin and MRP1 were increased in LSCC tissues (LSCC) compared with adjacent control tissues (control). $\beta$-Actin was detected as a loading control in the western blot. d The intensity of ubiquitinated peptides of vimentin and MRP1 in adjacent lung tissue samples (control) and LSCC tissues. Three independent experiments were conducted for each assay. * represent $p$ value $<0.05$, ** $p$ value $<$ 0.01 and $* * * p$ value $<0.001$

that vimentin and MRP1 were degraded through the UPS (Fig. 6a). Based on LSCC TCGA data, the mRNA level of VIM was significantly downregulated (Fig. 6b). The mRNA level of MRP1-encoded ABCC1 was significantly upregulated (Fig. 6b). Both vimentin and MRP1 were increased in the protein level in LSCC tissues (vimentin: fold change $=1.28$; MRP1: fold change $=1.78)$ (Fig. 6c). The ubiquitination intensities at residues $\mathrm{K}_{129}, \mathrm{~K}_{139}, \mathrm{~K}_{168}, \mathrm{~K}_{188}, \mathrm{~K}_{223}, \mathrm{~K}_{334}, \mathrm{~K}_{402}, \mathrm{~K}_{439}$, and $\mathrm{K}_{445}$ in vimentin were significantly decreased in LSCC tissues, with an average ratio $=0.38(p<0.01)$ (Fig. 6d). The ubiquitination intensities at residues $\mathrm{K}_{496}, \mathrm{~K}_{498}$, and $\mathrm{K}_{636}$ in MRP1 were significantly increased in LSCC tissues with the average intensity of ubiquitination $3.8 \times 10^{7}$, while those three ubiquitination sites were only detected in LSCC tissues (Fig. 6d). These results demonstrated that the increased protein expression of vimentin in LSCC was mainly derived from its decreased ubiquitination levels in LSCC, which caused the poorer survival status in LSCC, whereas the increased protein expression of MRP1 in LSCCs was mainly derived from its mRNA ABCC1 high expression in LSCC. Although the higher ubiquitination level increased MRP1 degradation, this degradation did not offset MRP1 synthesis due to its highly expressed mRNAs; thus, MRP1 was still increased in the protein level to cause the poorer survival status in LSCC. These results clearly demonstrated that ubiquitination regulated the intracellular protein abundance of vimentin and MRP1 by affecting the degradation of both proteins, which in turn affects the patient's prognosis.

\section{Identification of downstream biological processes and pathways mediated by vimentin and MRP1 in LSCC}

To further clarify the roles of the ubiquitinated vimentin and MRP1 in LSCC patient prognosis, the downstream biological processes and pathways mediated by vimentin and MRP1 were predicted. Totally, 1173 co-expressed genes were screened out for VIM (encoded vimentin) (Supplemental Table 4), and 183 co-expressed genes for ABCC1 (encoded MRP1) (Supplemental Table 5). Co-expressed genes of VIM were mainly involved in 65 statistically significant biological processes (Fig. 7a, Supplemental Table 6). Co-expressed genes of $\mathrm{ABCC} 1$ were mainly involved in 15 statistically significant biological processes (Fig. 7a, Supplemental Table 7). Among those co-expressed genes, ZC3H8, ANXA6, PMP22, RCCD1, and RFTN1 had high correlation coefficient with VIM, respectively, and WNT5A, ADAM23, ADH7, CZIB, and PHC2 had high correlation coefficient with $\mathrm{ABCC} 1$, respectively (Fig. 7b). Moreover, single gene GSEA analysis revealed that VIM was positively related to 15 statistically significant KEGG pathways (Fig. 7c, Supplemental Table 8), including cell migration, ECM receptor interaction, cell adhesion, immunity and inflammation, cytokine, cell apoptosis, MAPK signaling, and Jak-STAT signaling pathway. The high expression of $\mathrm{ABCC} 1$ was mainly related to 11 statistically significant KEGG pathways (Fig. 7c, Supplemental Table 9), including glutathione metabolism, porphyrin and chlorophyll metabolism, starch and sucrose metabolism, ascorbate and aldarate metabolism, steroid hormone biosynthesis, glycosaminoglycan biosynthesis, and glycosylphosphatidylinosito GPI anchor biosynthesis.

\section{Prediction of TRIM2 and NEDD4L as E3 ligases of vimentin and MRP1 in LSCC}

Totally, 30 E3s were predicted to catalyze the formation of vimentin ubiquitination (Supplemental Table 10), and 45 E3s were predicted to catalyze the formation of MRP1 ubiquitination (Supplemental Table 11). The top 20 E3s were shown for vimentin and MRP1, respectively (Fig. 8). The top $5 \mathrm{E} 3 \mathrm{~s}$ for vimentin ubiquitination come from the RING family, including TRIM2, SYVN1, TRIM32, TRIM3, and MIB1, with the confidence score from 0.687 to 0.728 , and TRIM2 has the highest confidence score of 0.728 . The top 5 E3s for MRP1 were NEDD4L, SYVN1, GNB2, NEDD4, and AMFR, with a confidence score from 0.668 to 0.829 , and NEDD4L had the highest confidence score of 0.829. It indicated that TRIM2 and NEDD4L might be the E3 ligases for vimentin and MRP1 in LSCC tissues, respectively.

\section{Discussion}

Ubiquitination is an important molecular event in LSCC, and the study on ubiquitination might lead to clarify new molecular mechanism and promote the PPPM of LSCC. This study reported the first ubiquitinomics study in LSCC tissues and identified 400 DUPs with 654 ubiquitination sites. These DUPs were mainly involved in four molecular network systems, including UPS, cell energy metabolism, cell-cell adhesion, and cell signal transduction, which are the precious resource to identify abnormally ubiquitinated protein 

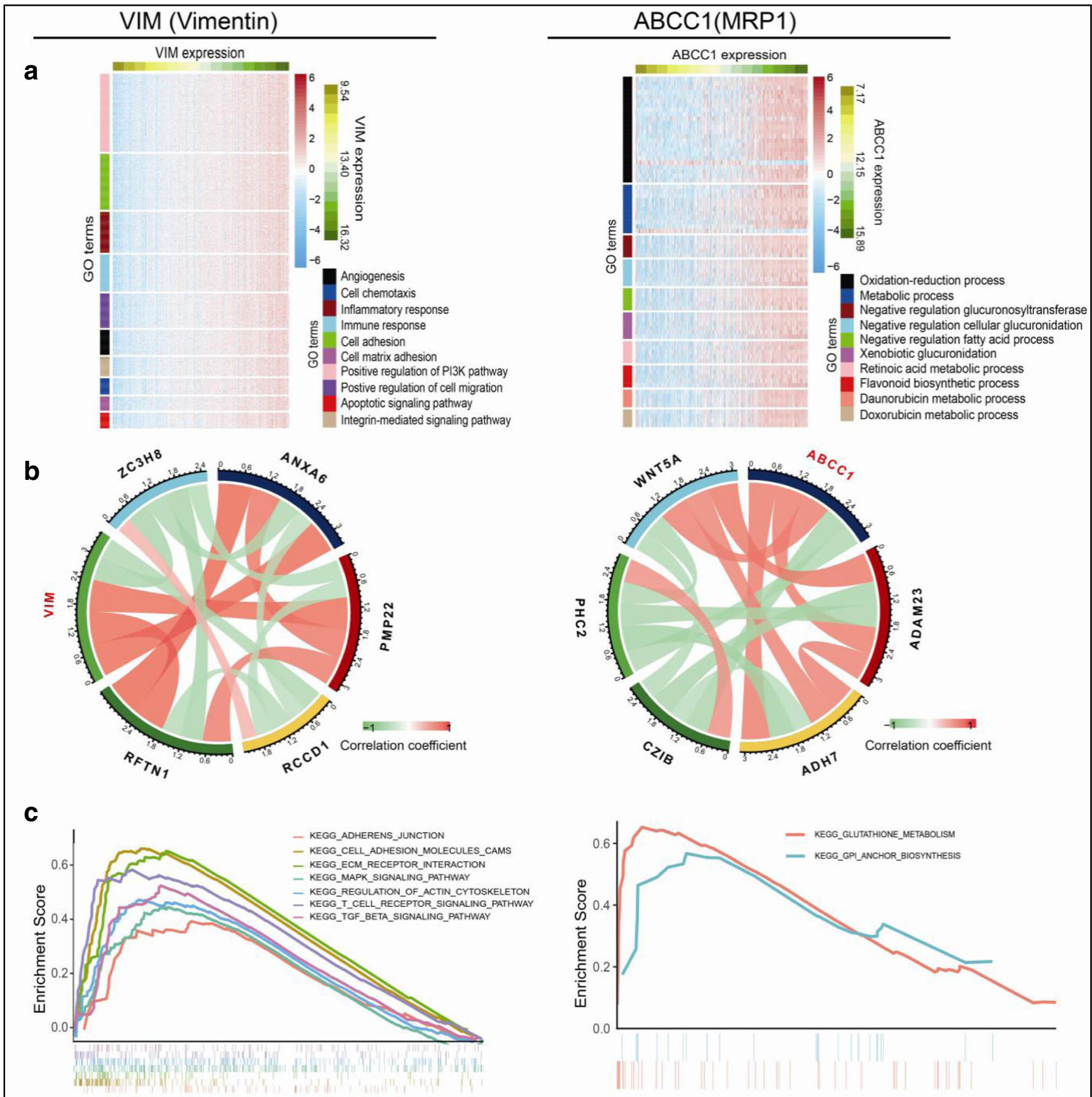

Fig. 7 Roles of vimentin and MRP1 in human LSCCs. a Based on cBioPortal and TCGA databases, GO analysis revealed important BPs of 1173 co-expressed genes for VIM and 183 co-expressed genes for $\mathrm{ABCC} 1$ in heat map. Each row represents the gene enriched in each GO term, and the color intensity is determined by the mRNA expression level of this gene. Each column represents a sample derived from TCGA

biomarkers for PPPM practice in LSCC. Ubiquitinationinvolved molecular network alterations not only reflect the roles of ubiquitination in the occurrence and development of LSCC, but also provide an important data to mine biomarkers for tumor diagnosis, prognosis, and new therapeutic targets from the components of UPS (such as E3 ligases and database of human LSCC. All samples were sorted from low to high according to the mRNA expression levels of VIM and ABCC1. b Coexpressed genes of VIM and $\mathrm{ABCC} 1$ with high correlation coefficient. $\mathbf{c}$ GSEA analysis revealed tumor-related KEGG pathways positively correlated with high expression of VIM and $\mathrm{ABCC} 1$

proteasome). Those ubiquitinomics data in combination with transcriptomics data and clinical data ( $n=494$ LSCC patients) from the TCGA database discovered two prognosis-related DUPs (vimentin and MRP1). Ubiquitination regulated the intracellular protein abundance of vimentin and MRPI to affect the prognosis of LSCC patients, namely ubiquitination- 


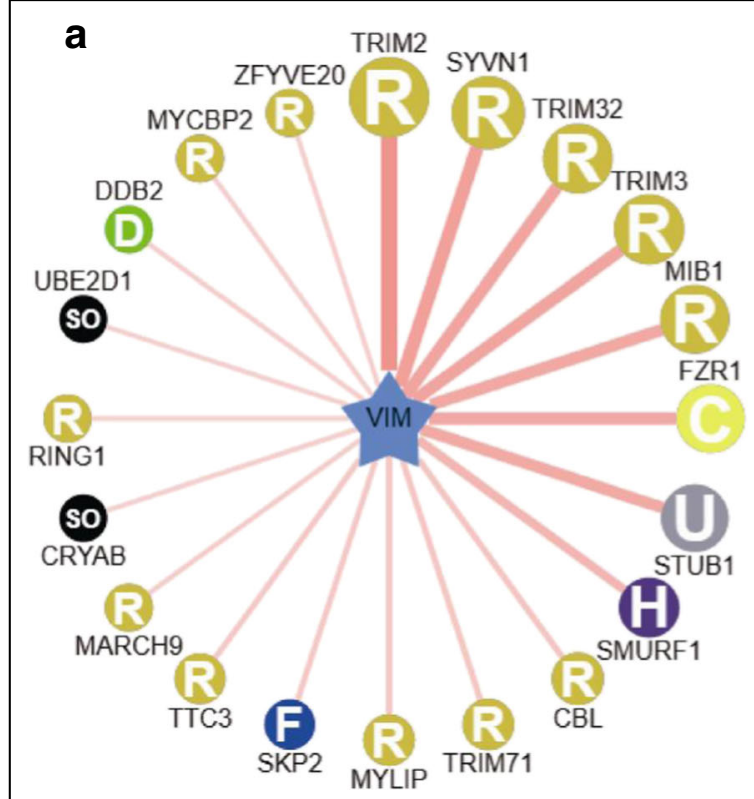

Fig. 8 Potential upstream mechanisms that cause ubiquitination of vimentin and of MRP1. a Top 20 potential E3s of vimentin. b Top 20 potential E3s of ABCC1. Note: MRP1 is coded by gene ABCC1. The solid line means VIM or $\mathrm{ABCC} 1$ directly interacts with its $\mathrm{E} 3$-substrates. The line thickness means the interaction intensity. TRIM2 has the highest interaction intensity with vimentin. NEDD4L has the highest interaction

mediated highly expressed vimentin and MRPI were associated with the poor prognosis of LSCC patient. Here, we will discuss in detail the ubiquitination-related molecular network alterations and clinical application value of ubiquitination in combination with multiomics in LSCC.

\section{Proteasome subunit ubiquitination contributes to UPS dysfunction}

The proteasome is a pivotal component of UPS to degrade the short-lived regulatory proteins, and remove the damaged soluble proteins [46]. Proteasome dysfunction decreases proteolytic activities and increases the accumulation of misfolded or damaged proteins, which may contribute to cancer pathogenesis [47]. The $26 \mathrm{~S}$ proteasome is consisted of two 19S regulatory cap subunits and one 20S subunit. Two 19S subunits are indispensable for the normal function of 20S subunit. For example, Rpn10 and Rpn13 were important recognition receptors of ubiquitinated target proteins $[48,49]$. Further, except for ubiquitination, many other PTMs such as phosphorylation, acetylation, and myristoylation were also identified in those subunits. Thus, these multiple PTMs greatly complicated the mechanisms to modulate proteasome activities. Studies found that mono-ubiquitination in Rpn10 was involved in the recruitment of substrate and interacted proteasome shuttle factor in Drosophila [50, 51], while the amino acid deprivation that induced ubiquitination of multiple 19S proteasome subunits (Rpn1, Rpn10, and Rpn13) was essential for

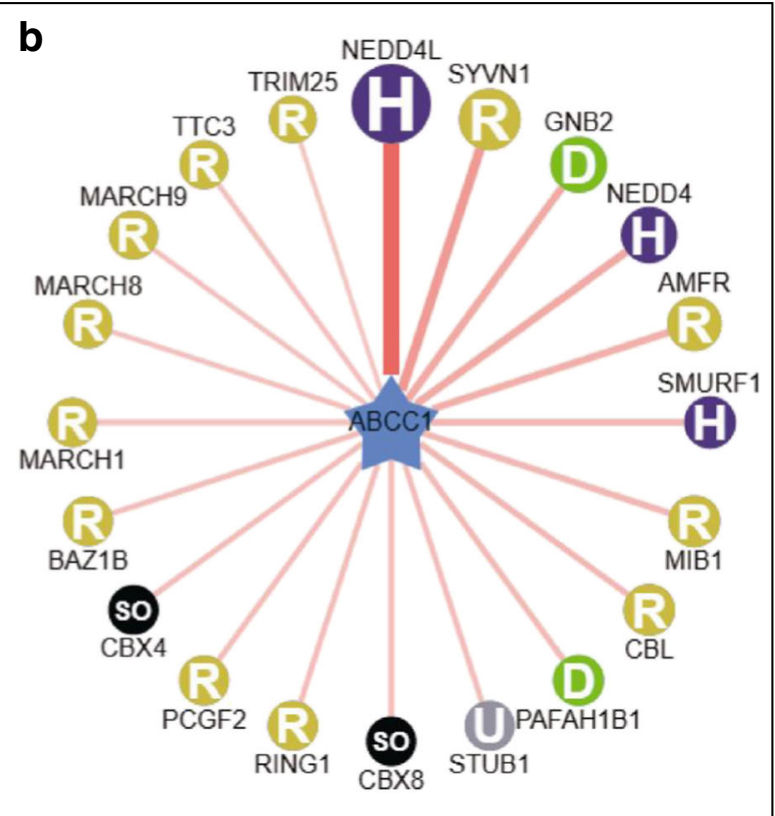

intensity with MRP1. H, R, D, U, F, and SO are the subfamilies of E3s. H: HECT (homologous to the E6-AP carboxyl terminus) E3 ligases. R: RING-finger E3 ligases. D: CUL4-DDB1-DWD (Cullin 4-Damaged DNA Binding1-DDB1 binding WD40) E3 ligases. U: U-box E3 ligases. F: F-box E3 ligases. SO: single other E3 ligases such as CRYAB, CKS1B, $\mathrm{UBE} 3 \mathrm{C}$, and $\mathrm{BRCC} 3$

autophagy of proteasome [52]. All the six identified DUPs in LSCC tissues belonged to $19 \mathrm{~S}$ regulatory subunit, namely three ATPase subunits (PSMC1, PSMC4, and PSMC6) and three nonATPase subunits (PSMD3, PSMD11, and PSMD12), which showed that ubiquitination of these 19S regulatory subunits might affect the assembly and activity of proteasome. Previous studies discovered that PSMD11 was required for proteasome assembly and played a crucial role in elevated proteasome activity in embryonic stem cells [53]. Moreover, acetylation [54], phosphorylation [55], and SUMO modification [56] were also found in PSMD11, and our study found ubiquitination in PSMD11 for the first time and identified one ubiquitination site at residue $\mathrm{K}_{32}$ only in LSCC tissues. At present, there are few studies on the effects of ubiquitination on the functions of various subunits of proteasome. However, considering the important functions of these proteasome subunits, these identified DUPs might reflect the functional abnormalities of proteasome in LSCC tissues compared to control tissues and ultimately lead to the imbalance of intracellular proteins. Therefore, our identified ubiquitination of proteasome subunits benefit for the indepth understanding of UPS functionary regulations.

\section{Ubiquitination plays an important role in LSCC metabolic reprogramming}

Metabolic reprogramming is a hallmark of cancer [57]. Tumor cells remodel their metabolism and energy production through 
confining energy metabolism mostly to glycolysis even under aerobic conditions, namely "aerobic glycolysis" [58]. This study revealed that DUPs were significantly involved in cellular energy metabolism-related pathways such as glycolysis/ gluconeogenesis and central carbon metabolism in cancer. Here, glycolysis/gluconeogenesis pathways were taken for example; seven DUPs were identified, namely triosephosphate, phosphoglycerate kinase 1, pyruvate kinase (PK), fructosebisphosphate aldolase A, glyceraldehyde-3-phosphate dehydrogenase (GAPDH), enolase 1, and L-lactate dehydrogenase B chain (LDH), and those DUPs were all enzymes and played important roles in the regulation of glycolysis and were associated with cancer. For example, GAPDH (P04406) was a glycolytic enzyme to specifically catalyze glyceraldehyde-3-phosphate (G-3-P) to D-glycerate 1, 3-bisphosphate. Although GAPDH was commonly regarded as a constitutive housekeeping gene, recent studies revealed that its expression status varied in different cancers [59]. Compared to normal lung tissue, GAPDH in both mRNA and proteins levels were upregulated in lung cancer tissue, which might contribute to the increased "aerobic glycolysis" [60]. Besides glycolysis, GAPDH as a multifunctional protein also participated in numerous biological processes [61]. For example, GAPDH bond to another cellular energy metabolismrelated DUP-LDH to form transcriptional coactivator complex, which clearly demonstrated the relationship of energy metabolism and gene transcription [62]. Pyruvate kinase (PK, P14618) was another cancer-related protein to catalyze the last irreversible reaction in the glycolytic pathway. PK was overexpressed in lung cancer and necessary for aerobic glycolysis [63]. Moreover, the overexpressed PK promoted tumor growth, and phosphorylation at residue $\mathrm{Tyr}_{105}$ in PKM2 might also contribute to the tumor growth [64]. Ubiquitinated $\mathrm{K}_{270}$ in PKM was only identified in LSCC tissues, which was important because it was both the substrate-binding site and transition state stabilizer site. The ubiquitination of key enzymes in the glycolysis pathway affected their abundance and (or) functions, which in turn affected the metabolic processes of the entire tumor cells. Further, there was a close relationship between cellular energy metabolism and UPS. Proteasome degradation of proteins required ATP consumption, so insufficient energy production would inevitably impair UPS. Conversely, abnormal UPS function might affect the turnover of key proteins in energy metabolism, which affected the energy production of cells. Abnormal energy metabolism and abnormal function of proteasome formed a vicious circle.

\section{Abnormal ubiquitination is closely related to tumor invasion and distant metastasis}

The abnormal cell adhesion is an important cause of tumor invasion and distant metastasis. Our study found that DUPs were mainly enriched in two cell adhesion-associated pathwaystight junction and adherens junction. Tight junction was taken as an example to explain the effect of ubiquitination on cell adhesion. A variety of proteins in tight junction were associated with invasion and metastasis of tumor. This study identified CLDN18 (P56856), belonging to the large protein family of claudin, participated in the maintenance of epithelial and endothelial tight junctions. Considering the inconsistent changes in CLDN among different tumor types, claudins had a high tissue specificity, which might be specific biomarkers for many types of cancers [65]. In addition, some preclinical studies found that CLDNs could be novel anti-tumor drug targets for cancer cells with high expression of CLDNs [66]. The exact function of CLDN18 in LSCC remains unknown. Ubiquitination at residue $\mathrm{K}_{239}$ in CLDN18 was only identified in normal tissue, and the ubiquitination intensity at residue $\mathrm{K}_{257}$ in CLDNs was downregulated. However, the effect of ubiquitination at residues $\mathrm{K}_{239}$ and $\mathrm{K}_{257}$ in CLDN18 remains unclear, and it is worth further exploring in the next step. Another DUP, ITGB1 (P05556) belonged to the integrin family, which is linked with various proteins in ECM and actin cytoskeleton to support cell adhesion and anchorage, which was crucial for tissue maintenance and repair in their structural role [42]. ITGB1 was an important beta subset, because it could regulate cell migration and was regarded as a prometastatic gene for lung cancer [67]. ITGB1 also participated in signal transduction; for example, ITGB1 was an important part of IL1B receptor and essential for IL1B signaling [68]. Those findings clearly demonstrated that abnormal ubiquitination contributed to tumor invasion and distant metastasis.

\section{Ubiquitination in combination with other PTMs regulates signaling pathways}

Ubiquitination as a common PTM also coexists with other PTMs to regulate cell signaling pathways, such as sustaining proliferative signaling that is another hallmark of tumor [56]. The above discussed tumor energy metabolism-related pathways and cell adhesion-related pathways were closely related to cell signal transduction system. The intermediate products of energy metabolism-related pathways and downstream molecules of cell adhesion-related pathway were important cell signaling molecules. For instance, GAPDH could regulate transcription as part of the transcription complex [61], while integrin interacted directly with GTPases family and played an important role in cell signal transduction [69]. This study found multiple tumor-related cell signal transduction pathways, including PI3K-AKT, RAP1 signaling, and cGMPPKG signaling pathways. Some molecules in these pathways were closely related to tumorigenesis, which were identified as DUPs, including Rac (A0A024R1P2), RhoA (A0A024R324), PP2A (A0A140VJT0, A0A140VJS0), ITGB1 (P05556), and IGF1R (P08069). A lot of literature showed the relationship between these molecules and cancers, and found that ubiquitination and other PTMs such as phosphorylation had some similarities and crosstalk. For example, ubiquitination and phosphorylation all consumed ATPs and 
were reversible enzyme-catalyzed reactions. Also, phosphorylation could regulate E3 ligase activity, create phosphodegrons, and regulate substrate localization, whereas ubiquitination could degrade protein kinases or activate protein kinases in some circumstances [70]. It is well-known that residues lysine, serine, threonine, and tyrosine often co-exist in a same protein. Thus, multiple PTMs such as ubiquitination or acetylation at residue lysine and phosphorylation at residues serine, threonine, and tyrosine might simultaneously occur in the same protein in a given condition. The cross-talks among multiple PTMs in a protein might greatly complicate biological network regulation processes and protein functions. Therefore, ubiquitination in combination with other PTMs might play important roles in regulating signaling pathway in LSCC.

\section{Multiomics integration analysis as a powerful tool to promote PPPM}

Biological omics is driving the paradigm shift of cancer research and treatment from a single-parameter model to a multiparameter model $[10,11]$. Meanwhile, PPPM strategy in cancer requires multiomics integration analysis, which can systematically explore the molecular mechanisms behind tumorigenesis $[8,9,71-73]$, and this study is an excellent example. The integration analysis of DUP profile and transcriptomics data with clinical information from the TCGA database ( $n=494$ LSCC patients) identified two prognosisrelated DUPs (vimentin and MRP1), which emphasized the important clinical value of ubiquitination for LSCC patient prognosis. Vimentin along with actin microfilaments and microtubules makes up the cytoskeleton to maintain cell shape and integrity of the cytoplasm [74]. Vimentin also functions as an organizer of a number of other important proteins involved in cell adhesion, signal transduction, and migration [74]. Recently, vimentin is identified as an epithelial-mesenchymal transition (EMT) biomarker, but one does not know the exact roles of vimentin in the EMT process [74]. Our study found that vimentin might affect EMT by participating in adherens junction, cell adhesion molecules cams, and MAPK signaling pathway. MRP1 is a member of the superfamily of ATP-binding cassette transporters to deliver various anti-tumor drugs to outside of tumor cells; thus, the decreased drug concentration inside of a cell will weaken its anticancer effect [75]. The UPS plays an important role in the regulation of intracellular abundance of vimentin and MRP1. Therefore, an in-depth analysis of the biological functions mediated by vimentin and MRP1 can benefit for the precise development of UPS-targeted antitumor drugs. Also, these analyses can provide a basis for the combined application of anti-tumor drugs. For example, one study demonstrated the important role of MRP1 in doxorubicin (DOX) resistance and the inhibitory effects of
MK571 (MRP1 inhibitor) in the DOX efflux and resistance in NSCLCs [76]. Thus, the combination of one drug targeting UPS to promote MRP1 degradation and an inhibitor of MRP1 might improve the prognosis of the patient more than a single drug alone. Similarly, our study found that vimentin was involved in regulating MAPK signaling pathway. It might be more effective to combine the use of a drug promoting vimentin degradation and a drug targeting the MAPK pathway. By now, only two DUPs (vimentin and MRP1) have been identified to be degraded by UPS and be associated with LSCC prognosis. However, we strongly believe that multiomics integration analysis can be used as a powerful tool to explore the role of ubiquitination in carcinogenesis and promote PPPM practice in LSCC.

\section{Conclusions and expert recommendations}

Label-free quantitative ubiquitinomics is an effective approach to identify DUPs and ubiquitination sites in human LSCC tissues. A total of 400 DUPs were identified in human LSCC vs. control tissues. GO and KEGG analyses revealed the important roles of ubiquitination in tumorigenesis and progress, and ubiquitination-involved molecular network alternations in LSCC, including UPS, energy metabolism, cell adhesion, and signal transduction. These findings not only reflect the important roles of ubiquitination in LSCC, but also provide a precious scientific data to mine biomarkers for tumor diagnosis, prognosis, and new therapeutic targets, for example, based on the identified DUPs in UPS (such as E3 ligases and proteasome). Further, integration analysis of DUP profile and transcriptomics data with clinical information from TCGA database $(n=494$ LSCC patients) identified two DUPs (vimentin and MRP1), which were regulated by UPS to cause the high expressions of vimentin and MRP1 that were associated with poor prognosis of LSCC. Thus, the ubiquitination levels of vimentin and MRP1 might be used as a biomarker for prognosis of LSCC patients. These findings clearly demonstrated that multiomics integration analysis can be regarded as a power tool to mine abnormally ubiquitinated protein biomarkers and new drug targets for PPPM practice in LSCC.

We recommend this article to promote ubiquitinomebased signaling pathway network analysis in LSCC from a systems biology angle, and emphasize the importance of multiomics such as ubiquitinomics in combination with transcriptomics and large-scale clinical data in the basic research and translational research for PPPM in LSCC [74]. Here, we propose that ubiquitination-involved signaling pathway network alterations in combination with multiomics analysis to identify reliable biomarkers are an effective approach to clarify molecular mechanisms and discover effective therapeutic targets for personalized 
treatment of LSCC. Also, those DUPs and survivalrelated hub molecules are precious resources to discover real pattern biomarkers for LSCC.

Authors' contributions M. L. collected tissue samples, analyzed the data, prepared the figures and tables, performed cell culture and western blot experiments, and designed and wrote the manuscript. W.C. carried out the LC-MS/MS experiment. W.Z. provided clinical tissue samples with clinical diagnosis. X.Z. conceived the concept; designed the experiments and manuscript; obtained LC-MS/MS data, instructed experiments and data analysis; supervised the results; coordinated, wrote, and critically revised the manuscript; and was responsible for its financial support and the corresponding works. All the authors approved the final manuscript.

Funding information This work was supported by the Hunan Provincial Hundred Talent Plan (to XZ) and the Xiangya Hospital Funds for Talent Introduction (to XZ) and grants from the China "863" Plan Project (Grant No. 2014AA020610-1 to XZ), National Natural Science Foundation of China (Grant Nos. 81572278 and 81272798 to XZ), and Hunan Provincial Natural Science Foundation of China (Grant No. 14JJ7008 to XZ).

\section{Compliance with ethical standards}

Competing interests The authors declare that they have no conflict of interest.

Ethical approval All the patients were informed about the purposes of the study and, consequently, have signed their "consent of the patient". All investigations conformed to the principles outlined in the Declaration of Helsinki and were performed with permission by the responsible Medical Ethics Committee of Xiangya Hospital, Central South University, China.

Open Access This article is licensed under a Creative Commons Attribution 4.0 International License, which permits use, sharing, adaptation, distribution and reproduction in any medium or format, as long as you give appropriate credit to the original author(s) and the source, provide a link to the Creative Commons licence, and indicate if changes were made. The images or other third party material in this article are included in the article's Creative Commons licence, unless indicated otherwise in a credit line to the material. If material is not included in the article's Creative Commons licence and your intended use is not permitted by statutory regulation or exceeds the permitted use, you will need to obtain permission directly from the copyright holder. To view a copy of this licence, visit http://creativecommons.org/licenses/by/4.0/.

\section{References}

1. Socinski MA, Obasaju C, Gandara D, Hirsch FR, Bonomi P, Bunn PA Jr, et al. Current and emergent therapy options for advanced squamous cell lung cancer. J Thorac Oncol. 2018;13:165-83. https://doi.org/10.1016/j.jtho.2017.11.111.

2. Zhang X-C, Wang J, Shao G-G, Wang Q, Qu X, Wang B, et al. Comprehensive genomic and immunological characterization of Chinese non-small cell lung cancer patients. Nat Commun. 2019;10:1772. https://doi.org/10.1038/s41467-019-09762-1.

3. Network CGAR. Comprehensive genomic characterization of squamous cell lung cancers. Nature. 2012;489:519-25. https:// doi.org/10.1038/nature11404.
4. Weiss J, Sos ML, Seidel D, Peifer M, Zander T, Heuckmann JM, et al. Frequent and focal FGFR1 amplification associates with therapeutically tractable FGFR1 dependency in squamous cell lung cancer. Sci Transl Med. 2010;2:62ra93. https://doi.org/10.1126/ scitranslmed.3001451.

5. Hammerman PS, Sos ML, Ramos AH, Xu C, Dutt A, Zhou W, et al. Mutations in the DDR2 kinase gene identify a novel therapeutic target in squamous cell lung cancer. Cancer Discov. 2011;1:78 89. https://doi.org/10.1158/2159-8274.CD-11-0005.

6. Qian S, Golubnitschaja O, Zhan X. Chronic inflammation: key player and biomarker-set to predict and prevent cancer development and progression based on individualized patient profiles. EPMA J. 2019;10:365-81. https://doi.org/10.1007/s13167-01900194-x.

7. Baban B, Golubnitschaja O. The potential relationship between Flammer and Sjögren syndromes: the chime of dysfunction. EPMA J. 2017;8:333-8. https://doi.org/10.1007/s13167-0170107-5.

8. Gerner C, Costigliola V, Golubnitschaja O. MULTIOMIC patterns in body fluids: technological challenge with a great potential to implement the advanced paradigm of $3 \mathrm{P}$ medicine. Mass Spectrom Rev. 2019. https://doi.org/10.1002/mas.21612.

9. Golubnitschaja O, Polivka J, Yeghiazaryan K, Berliner L. Liquid biopsy and multiparametric analysis in management of liver malignancies: new concepts of the patient stratification and prognostic approach. EPMA J. 2018;9:271-85. https://doi.org/10.1007/ s13167-018-0146-6.

10. Cheng T, Zhan X. Pattern recognition for predictive, preventive, and personalized medicine in cancer. EPMA J. 2017;8:51-60. https://doi.org/10.1007/s13167-017-0083-9.

11. Lu M, Zhan X. The crucial role of multiomic approach in cancer research and clinically relevant outcomes. EPMA J. 2018;9:77102. https://doi.org/10.1007/s13167-018-0128-8.

12. Zhan X, Long Y, Lu M. Exploration of variations in proteome and metabolome for predictive diagnostics and personalized treatment algorithms: innovative approach and examples for potential clinical application. J Proteome. 2018;188:30-40. https://doi.org/10.1016/j. jprot.2017.08.020.

13. Zhan X, Yang H, Peng F, Li J, Mu Y, Long Y, et al. How many proteins can be identified in a 2DE gel spot within an analysis of a complex human cancer tissue proteome? Electrophoresis. 2018;39: 965-80. https://doi.org/10.1002/elps.201700330.

14. Ciechanover A. The ubiquitin-proteasome proteolytic pathway. Cell. 1994;79:13-21. https://doi.org/10.1016/0092-8674(94) 90396-4.

15. Kimura Y, Tanaka K. Regulatory mechanisms involved in the control of ubiquitin homeostasis. J Biochem. 2010;147:793-8. https:// doi.org/10.1093/jb/mvq044.

16. Komander D, Rape M. The ubiquitin code. Annu Rev Biochem. 2012;81:203-29.

17. Herhaus L, Dikic I. Expanding the ubiquitin code through posttranslational modification. EMBO Rep. 2015;16:1073-83. https:// doi.org/10.15252/embr.201540891.

18. Kessler BM. Ubiquitin — omics reveals novel networks and associations with human disease. Curr Opin Chem Biol. 2013;17:59-65. https://doi.org/10.1016/j.cbpa.2012.12.024.

19. Gerlach B, Cordier SM, Schmukle AC, Emmerich CH, Rieser E, Haas TL, et al. Linear ubiquitination prevents inflammation and regulates immune signalling. Nature. 2011;471:591-6. https://doi. org/10.1038/nature09816.

20. Arnaud L, Robakis NK, Figueiredo-Pereira ME. It may take inflammation, phosphorylation and ubiquitination to 'tangle' in Alzheimer's disease. Neurodegener Dis. 2006;3:313-9. https:// doi.org/10.1159/000095638.

21. Uramova S, Kubatka P, Dankova Z, Kapinova A, Zolakova B, Samec M, et al. Plant natural modulators in breast cancer 
prevention: status quo and future perspectives reinforced by predictive, preventive, and personalized medical approach. EPMA J. 2018;9:403-19. https://doi.org/10.1007/s13167-018-0154-6.

22. Mani A, Gelmann EP. The ubiquitin-proteasome pathway and its role in cancer. J Clin Oncol. 2005;23:4776-89. https://doi.org/10. 1200/JCO.2005.05.081

23. Adams J, Kauffman M. Development of the proteasome inhibitor Velcade $^{\mathrm{TM}}$ (bortezomib). Cancer Investig. 2004;22:304-11. https:// doi.org/10.1081/cnv-120030218.

24. Vij R, Siegel DS, Jagannath S, Jakubowiak AJ, Stewart AK, McDonagh K, et al. An open-label, single-arm, phase 2 study of single-agent carfilzomib in patients with relapsed and/or refractory multiple myeloma who have been previously treated with bortezomib. Br J Haematol. 2012;158:739-48. https://doi.org/10. 1111/j.1365-2141.2012.09232.x.

25. Low TY, Magliozzi R, Guardavaccaro D, Heck AJ. Unraveling the ubiquitin-regulated signaling networks by mass spectrometry-based proteomics. Proteomics. 2013;13:526-37. https://doi.org/10.1002/ pmic.201200244.

26. Wu Q, Cheng Z, Zhu J, Xu W, Peng X, Chen C, et al. Suberoylanilide hydroxamic acid treatment reveals crosstalks among proteome, ubiquitylome and acetylome in non-small cell lung cancer A549 cell line. Sci Rep. 2015;5:9520. https://doi.org/ 10.1038/srep09520.

27. Qin X, Chen S, Qiu Z, Zhang Y, Qiu F. Proteomic analysis of ubiquitination-associated proteins in a cisplatin-resistant human lung adenocarcinoma cell line. Int J Mol Med. 2012;29:791-800. https://doi.org/10.3892/ijmm.2012.912.

28. Cline MS, Craft B, Swatloski T, Goldman M, Ma S, Haussler D, et al. Exploring TCGA pan-cancer data at the UCSC cancer genomics browser. Sci Rep. 2013;3:2652. https://doi.org/10.1038/ srep02652.

29. Devarakonda S, Morgensztern D, Govindan R. Clinical applications of The Cancer Genome Atlas project (TCGA) for squamous cell lung carcinoma. Oncology. 2013;27:899-906.

30. Chou MF, Schwartz D. Biological sequence motif discovery using motif-x. Curr Protoc Bioinformatics. 2011;35:13.5. 1-5. 24. https:// doi.org/10.1002/0471250953.bi1315s35.

31. Schwartz D, Gygi SP. An iterative statistical approach to the identification of protein phosphorylation motifs from large-scale data sets. Nat Biotechnol. 2005;23:1391-8. https://doi.org/10.1038/ nbt1146.

32. Wei Huang D, Sherman BT, Tan Q, Collins JR, Alvord WG, Roayaei J, et al. The DAVID Gene Functional Classification Tool: a novel biological module-centric algorithm to functionally analyze large gene lists. Genome Biol. 2007;8:1-16. https://doi.org/ 10.1186/gb-2007-8-9-r183.

33. Wu J, Mao X, Cai T, Luo J, Wei L. KOBAS server: a web-based platform for automated annotation and pathway identification. Nucleic Acids Res. 2006;34:W720-4. https://doi.org/10.1093/nar/ gk1167.

34. Xie C, Mao X, Huang J, Ding Y, Wu J, Dong S, et al. KOBAS 2.0: a web server for annotation and identification of enriched pathways and diseases. Nucleic Acids Res. 2011;39:W316-22. https://doi. org/10.1093/nar/gkr483.

35. Franceschini A, Szklarczyk D, Frankild S, Kuhn M, Simonovic M, Roth A, et al. STRING v9. 1: protein-protein interaction networks, with increased coverage and integration. Nucleic Acids Res. 2012;41:D808-15. https://doi.org/10.1093/nar/gks1094.

36. Smoot ME, Ono K, Ruscheinski J, Wang P-L, Ideker T. Cytoscape 2.8: new features for data integration and network visualization. Bioinformatics. 2010;27:431-2. https://doi.org/10.1093/ bioinformatics/btq 675 .

37. Robin X, Turck N, Hainard A, Tiberti N, Lisacek F, Sanchez J-C, et al. pROC: an open-source package for R and $\mathrm{S}+$ to analyze and compare ROC curves. BMC Bioinf. 2011;12:77. https://doi.org/10. 1186/1471-2105-12-77.

38. Perkins NJ, Schisterman EF. The inconsistency of "optimal" cutpoints obtained using two criteria based on the receiver operating characteristic curve. Am J Epidemiol. 2006;163:670-5. https:// doi.org/10.1093/aje/kwj063.

39. Gao J, Aksoy BA, Dogrusoz U, Dresdner G, Gross B, Sumer SO et al. Integrative analysis of complex cancer genomics and clinical profiles using the cBioPortal. Sci. Signal. 2013;6:pl1-pl. DOI: https://doi.org/10.1126/scisignal.2004088

40. Subramanian A, Tamayo P, Mootha VK, Mukherjee S, Ebert BL, Gillette MA, et al. Gene set enrichment analysis: a knowledgebased approach for interpreting genome-wide expression profiles. Proc Natl Acad Sci U S A. 2005;102:15545-50. https://doi.org/10. 1073/pnas.0506580102.

41. Li Y, Xie P, Lu L, Wang J, Diao L, Liu Z, et al. An integrated bioinformatics platform for investigating the human E3 ubiquitin ligase-substrate interaction network. Nat Commun. 2017;8:347. https://doi.org/10.1038/s41467-017-00299-9.

42. Aplin AE, Howe AK, Juliano RL. Cell adhesion molecules, signal transduction and cell growth. Curr Opin Cell Biol. 1999;11:737-44. https://doi.org/10.1016/s0955-0674(99)00045-9.

43. Hu P, Wong PTY, Zhou Q, Sheng L, Niu W, Chen S, et al. Clinical relevance of the multidrug resistance-associated protein 1 gene in non-small cell lung cancer: a systematic review and meta-analysis. Oncol Rep. 2018;40:3078-91. https://doi.org/10.3892/or.2018. 6652.

44. Zhao J, Shi X, Wang T, Ying C, He S, Chen Y. The prognostic and clinicopathological significance of IGF-1R in NSCLC: a meta-analysis. Cell Physiol Biochem. 2017;43:697-704. https://doi.org/10. 1159/000480655.

45. Ye Z, Zhang X, Luo Y, Li S, Huang L, Li Z, et al. Prognostic values of vimentin expression and its clinicopathological significance in non-small cell lung cancer: a meta-analysis of observational studies with 4118 cases. PLoS One. 2016;11:e0163162. https://doi.org/10. 1371/journal.pone.0163162.

46. Etlinger JD, Goldberg AL. A soluble ATP-dependent proteolytic system responsible for the degradation of abnormal proteins in reticulocytes. Proc Natl Acad Sci U S A. 1977;74:54-8. https://doi. org/10.1073/pnas.74.1.54.

47. Ermolaeva MA, Dakhovnik A, Schumacher B. Quality control mechanisms in cellular and systemic DNA damage responses. Ageing Res Rev. 2015;23:3-11. https://doi.org/10.1016/j.arr.2014. 12.009 .

48. Husnjak K, Elsasser S, Zhang N, Chen X, Randles L, Shi Y, et al. Proteasome subunit Rpn13 is a novel ubiquitin receptor. Nature. 2008;453:481-8. https://doi.org/10.1038/nature06926.

49. Deveraux Q, Ustrell V, Pickart C, Rechsteiner M. A 26 S protease subunit that binds ubiquitin conjugates. J Biol Chem. 1994;269: 7059-61.

50. Isasa M, Katz EJ, Kim W, Yugo V, González S, Kirkpatrick DS, et al. Monoubiquitination of RPN10 regulates substrate recruitment to the proteasome. Mol Cell. 2010;38:733-45. https://doi.org/10. 1016/j.molcel.2010.05.001.

51. Zn L, Kovács L, Pt D, Udvardy A. Ubiquitylation of Drosophila p54/Rpn10/S5a regulates its interaction with the UBA-UBL polyubiquitin receptors. Biochemistry. 2012;51:2461-70. https:// doi.org/10.1021/bi3001006.

52. Cohen-Kaplan V, Livneh I, Avni N, Fabre B, Ziv T, Kwon YT, et al. p62- and ubiquitin-dependent stress-induced autophagy of the mammalian 26S proteasome. Proc Natl Acad Sci U S A. 2016;113:E7490-E9. https://doi.org/10.1073/pnas.1615455113.

53. Vilchez D, Boyer L, Morantte I, Lutz M, Merkwirth C, Joyce D, et al. Increased proteasome activity in human embryonic stem cells is regulated by PSMD11. Nature. 2012;489:304-8. https://doi.org/ 10.1038/nature11468. 
54. Van Damme P, Lasa M, Polevoda B, Gazquez C, Elosegui-Artola A, Kim DS, et al. N-terminal acetylome analyses and functional insights of the N-terminal acetyltransferase NatB. Proc Natl Acad Sci U S A. 2012;109:12449-54. https://doi.org/10.1073/pnas. 1210303109.

55. Wang X, Chen C-F, Baker PR, P-1 C, Kaiser P, Huang L. Mass spectrometric characterization of the affinity-purified human $26 \mathrm{~S}$ proteasome complex. Biochemistry. 2007;46:3553-65. https://doi. org/10.1021/bi061994u.

56. Hendriks IA, Treffers LW, Verlaan-de Vries M, Olsen JV, Vertegaal AC. SUMO-2 orchestrates chromatin modifiers in response to DNA damage. Cell Rep. 2015;10:1778-91. https://doi.org/10. 1016/j.celrep.2015.02.033.

57. Hanahan D, Weinberg RA. Hallmarks of cancer: the next generation. Cell. 2011;144:646-74. https://doi.org/10.1016/j.cell.2011.02. 013.

58. Vander Heiden MG, Cantley LC, Thompson CB. Understanding the Warburg effect: the metabolic requirements of cell proliferation. Science. 2009;324:1029-33. https://doi.org/10.1126/science. 1160809.

59. Caradec J, Sirab N, Revaud D, Keumeugni C, Loric S. Is GAPDH a relevant housekeeping gene for normalisation in colorectal cancer experiments? Br J Cancer. 2010;103:1475-6. https://doi.org/10. 1038/sj.bjc.6605851.

60. Cuezva JM, Chen G, Alonso AM, Isidoro A, Misek DE, Hanash $\mathrm{SM}$, et al. The bioenergetic signature of lung adenocarcinomas is a molecular marker of cancer diagnosis and prognosis. Carcinogenesis. 2004;25:1157-63. https://doi.org/10.1093/carcin/ bgh113.

61. Sheokand N, Malhotra H, Kumar S, Tillu VA, Chauhan AS, Raje $\mathrm{CI}$, et al. Moonlighting cell-surface GAPDH recruits apotransferrin to effect iron egress from mammalian cells. J Cell Sci. 2014;127: 4279-91. https://doi.org/10.1242/jcs.154005.

62. Zheng L, Roeder RG, Luo Y. S phase activation of the histone H2B promoter by OCA-S, a coactivator complex that contains GAPDH as a key component. Cell. 2003;114:255-66. https://doi.org/10. 1016/s0092-8674(03)00552-x.

63. Christofk HR, Vander Heiden MG, Harris MH, Ramanathan A, Gerszten RE, Wei R, et al. The M2 splice isoform of pyruvate kinase is important for cancer metabolism and tumour growth. Nature. 2008;452:230-3. https://doi.org/10.1038/nature06734.

64. Hitosugi T, Kang S, Vander Heiden MG, Chung T-W, Elf S, Lythgoe $\mathrm{K}$ et al. Tyrosine phosphorylation inhibits PKM2 to promote the Warburg effect and tumor growth. Sci. Signal. 2009;2: ra73-ra. DOI: https://doi.org/10.1126/scisignal.2000431

65. Morin PJ. Claudin proteins in human cancer: promising new targets for diagnosis and therapy. Cancer Res. 2005;65:9603-6. https://doi. org/10.1158/0008-5472.CAN-05-2782.
66. Kominsky SL. Claudins: emerging targets for cancer therapy. Expert Rev Mol Med. 2006;8:1-11. https://doi.org/10.1017/ S1462399406000056.

67. Wang X-M, Li J, Yan M-X, Liu L, Jia D-S, Geng Q, et al. Integrative analyses identify osteopontin, LAMB3 and ITGB1 as critical pro-metastatic genes for lung cancer. PLoS One. 2013;8: e55714. https://doi.org/10.1371/journal.pone.0055714.

68. Takada YK, Yu J, Fujita M, Saegusa J, Wu C-Y, Takada Y. Direct binding to integrins and loss of disulfide linkage in IL-1 $\beta$ are involved in the agonistic action of IL-1 $\beta$. J Biol Chem. 2017:jbc. M117. 818302. DOI: https://doi.org/10.1074/jbc.M117.818302.

69. Parise LV, Lee JW, Juliano R, editors. New aspects of integrin signaling in cancer. Semin Cancer Biol. 2000;10:407-14. https:// doi.org/10.1006/scbi.2000.0337.

70. Hunter T. The age of crosstalk: phosphorylation, ubiquitination, and beyond. Mol Cell. 2007;28:730-8. https://doi.org/10.1016/j. molcel.2007.11.019.

71. Li N, Zhan X. Signaling pathway network alterations in human ovarian cancers identified with quantitative mitochondrial proteomics. EPMA J. 2019:1-20. https://doi.org/10.1007/s13167-01900170-5.

72. Zhan X, Desiderio DM. Systems Biological aspects of Pituitary tumors. Front Endocrinol. 2016;7:86. https://doi.org/10.3389/ fendo.2016.00086.

73. Zhan X, Long Y. Exploration of Molecular network Variations in Different Subtypes of Human non-functional pituitary Adenomas. Front Endocrinol. 2016;7:13. https://doi.org/10.3389/fendo.2016. 00013.

74. Satelli A, Li S. Vimentin in cancer and its potential as a molecular target for cancer therapy. Cell Mol Life Sci. 2011;68:3033-46. https://doi.org/10.1007/s00018-011-0735-1.

75. Boumendjel A, Baubichon-Cortay H, Trompier D, Perrotton T, Di Pietro A. Anticancer multidrug resistance mediated by MRP1: recent advances in the discovery of reversal agents. Med Res Rev. 2005;25:453-72. https://doi.org/10.1002/med.20032.

76. Chen Y-L, Yang T-Y, Chen K-C, Wu C-L, Hsu S-L, Hsueh C-M. Hypoxia can impair doxorubicin resistance of non-small cell lung cancer cells by inhibiting MRP1 and P-gp expression and boosting the chemosensitizing effects of MRP1 and P-gp blockers. Cell Oncol. 2016;39:411-33. https://doi.org/10.1007/s13402-0160285-5.

Publisher's note Springer Nature remains neutral with regard to jurisdictional claims in published maps and institutional affiliations. 